\title{
IMPROVED DOWN-HOLE CPT TOOLS FOR THE DETECTION OF CHLORINATED SOLVENTS
}

\author{
Final Technical Report \\ Reporting Period: 7/30/97 - 11/30/98 \\ Prepared by: \\ Wesley L. Bratton, Ph.D., PE \\ Martin L. Gildea \\ Stephen P. Farrington, P.E. \\ Report Issued: November, 1998 \\ Prepared for: \\ U.S. Department of Energy \\ Morgantown Energy Technology Center \\ Morgantown, West Virginia \\ Under DOE Award Number: \\ DE-AR21-95MC31186--01
}

\section{Submitted by:}

Applied Research Associates, Inc.

New England Division

120-A Waterman Road

South Royalton, Vermont 05068

ARA Report No. 4534 


\section{DISCLAIMER}

This report was prepared as an account of work sponsored by an agency of the United States Government. Neither the United States Government nor any agency therefor, nor any of their employees, makes any warranty, express or implied, or assumes any legal liability or responsibility for the accuracy, completeness, or usefulness of any information, apparatus, product, or process disclosed, or represents that its use would not infringe privately owned rights. Reference herein to any specific commercial product, process, or service by trade name, trademark, manufacturer, or otherwise does not necessarily constitute or imply its endorsement, recommendation, or favoring by the United States Government or any agency thereof. The views and opinions of authors expressed herein do not necessarily state or reflect those of the United States Government or any agency thereof. 


\begin{abstract}
Conventional soil and groundwater sampling procedures present many opportunities for loss of volatile organic compounds (VOC) by exposing sample media to the atmosphere during transfers between sampling devices and containers, ultimately affecting the quality of the analytical results. Inaccurate characterization data often leads to improperly designed remedial systems that slow the clean-up process and increase the cost. For these reasons, in situ methods for sample extraction and real time analysis provide attractive alternatives to conventional sampling and analysis. Under funding from the U.S. Department of Energy's Federal Energy Technology Center (FETC), the investigators continued development of a system that combines High Speed Gas Chromatography techniques with Cone Penetration Testing to achieve near-real time analysis of soils and groundwater for chlorinated and aromatic hydrocarbon contamination (PCE, TCE, BTEX) during site characterization. The system combines three new CPT tools with an up-hole analyzer. The Dynamic Thermal Desorption (DTD) probe provides the up-hole analyzer with continuously sampled soil gas, enhancing detection limits by heating the soil matrix during penetration to thermally desorb volatile organic contaminants. The CPT In Situ Purge Probe (CISP) purges a water sample in situ, transferring the purge gas up-hole for analysis. Alternatively, soil gas or purge gas from the DTD probe or the CISP can be diverted to a Downhole Trap Module (DTM), which traps contaminants on conventional trap media for later analysis in a fixed laboratory. While the effectiveness of the CISP was hampered by the tendency of fine grained materials to clog its sample inlet filter, the DTD probe and the DTM were demonstrated to perform their intended functions well.
\end{abstract}




\section{TABLE OF CONTENTS}

$\begin{array}{lll}\text { Section } & \text { Page }\end{array}$

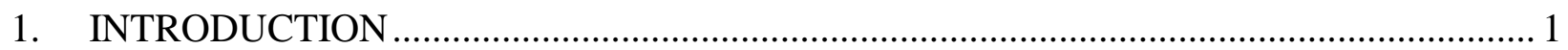

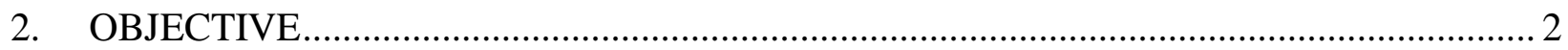

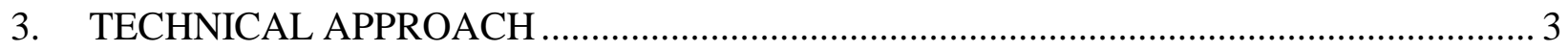

4. CPT SAMPLING EQUIPMENT DEVELOPMENT …............................................ 5

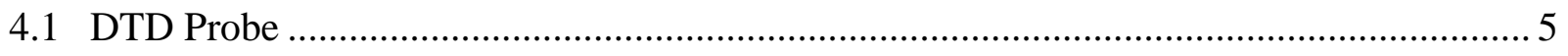

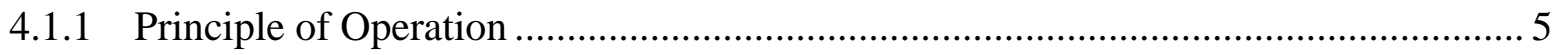

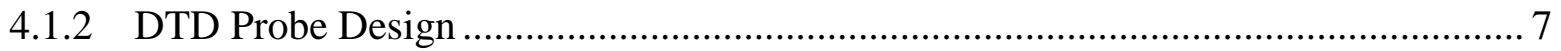

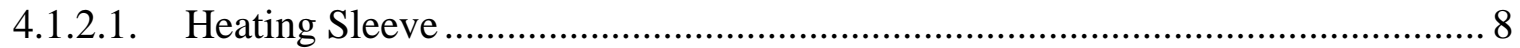

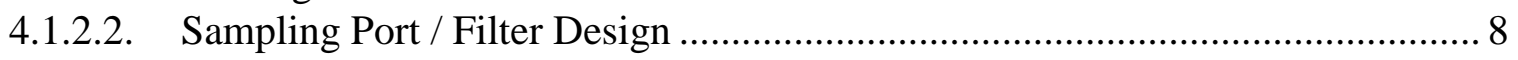

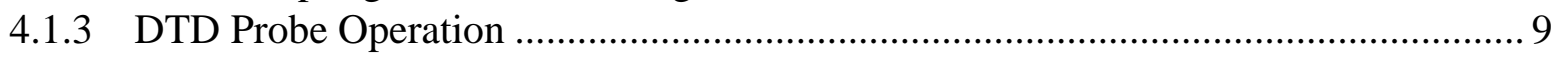

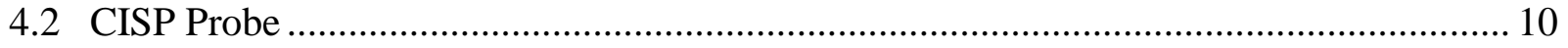

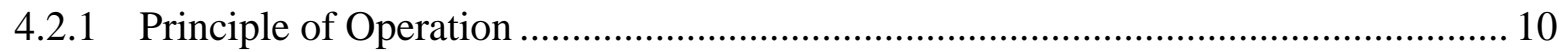

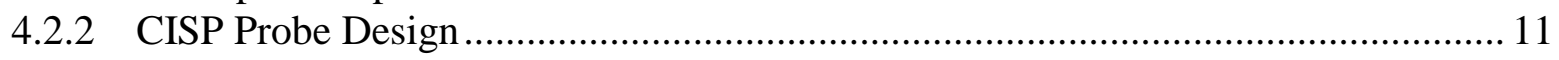

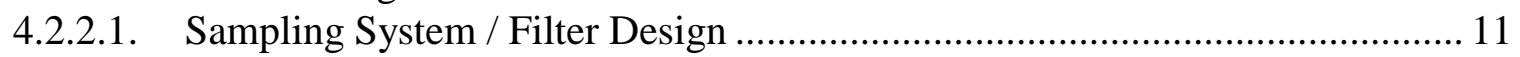

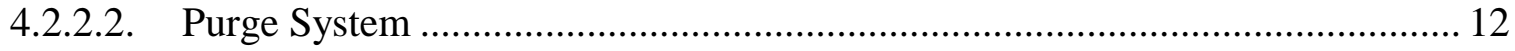

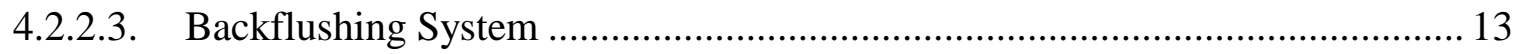

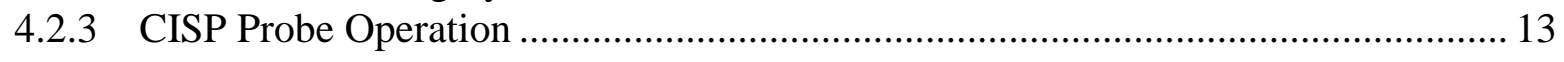

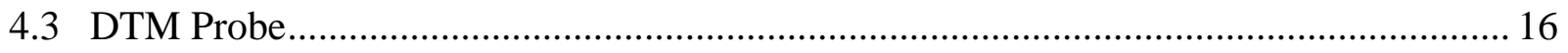

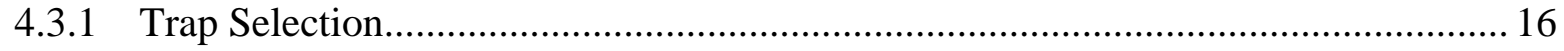

4.4 Heated Transfer Line Development \& Testing ..................................................... 17

4.4.1 Teflon Tubing Transfer Efficiency Comparison .............................................. 17

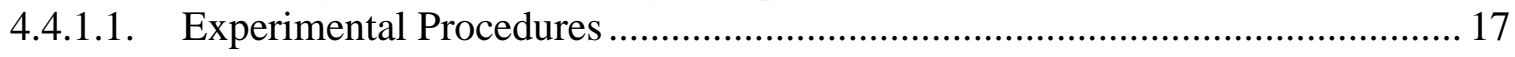

4.4.1.1.1. Tubing Preparation and Baseline Sample Collection................................. 17

4.4.1.1.2. Target Analyte Mixture Preparation........................................................ 17

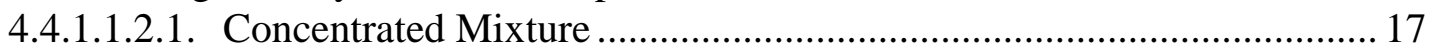

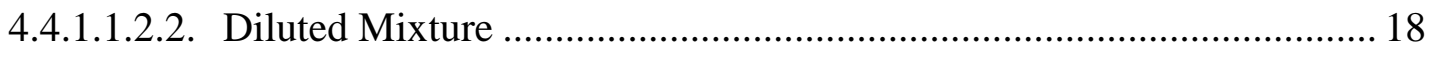

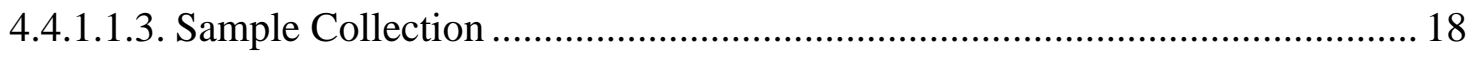

4.4.1.1.3.1. Initial Concentration Samples....................................................... 18

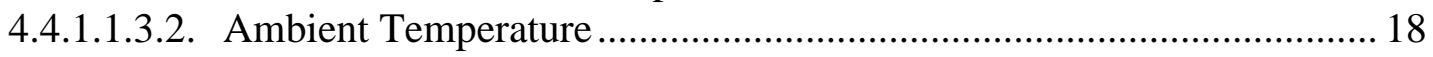

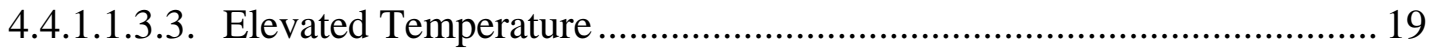

4.4.1.1.4. Sample Handling and Chemical Analysis .............................................. 19

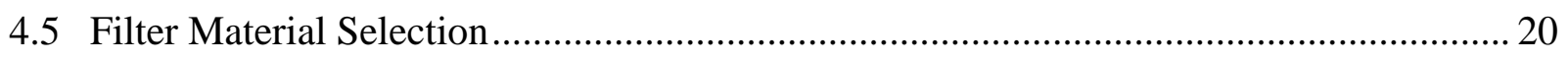

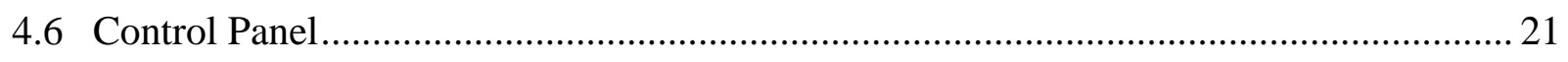

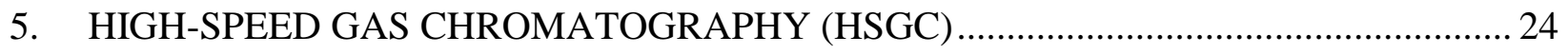

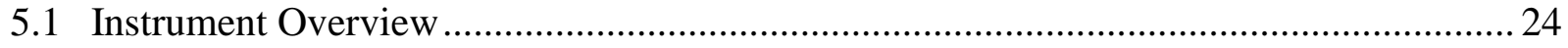




\section{TABLE OF CONTENTS (Continued)}

Section

Page

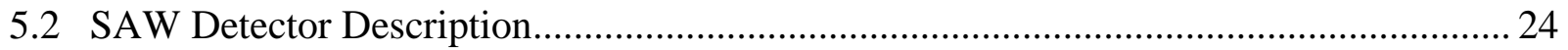

5.3 GC/SAW Fast Chromatography System …………………………………………....... 26

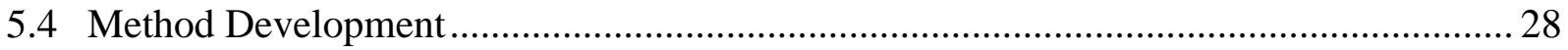

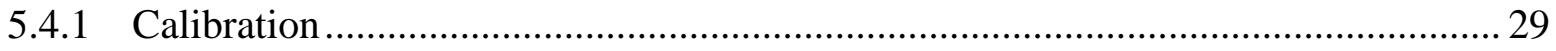

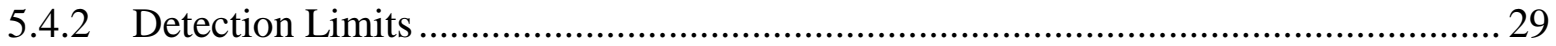

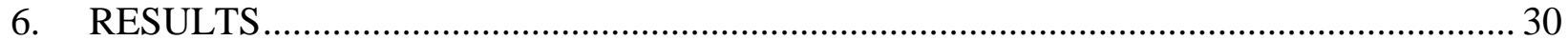

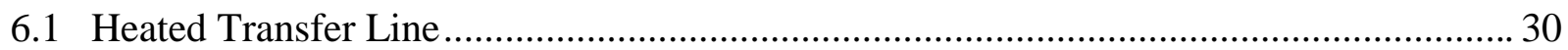

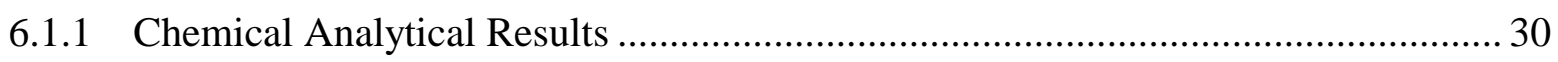

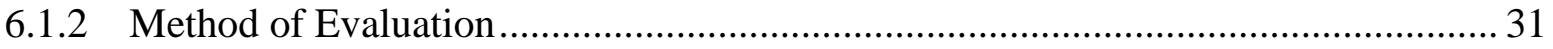

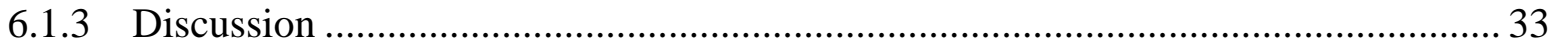

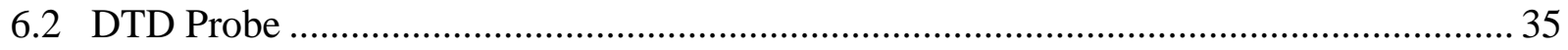

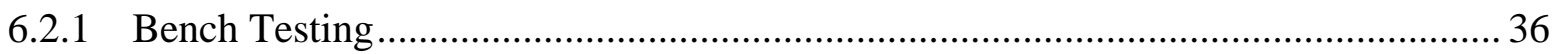

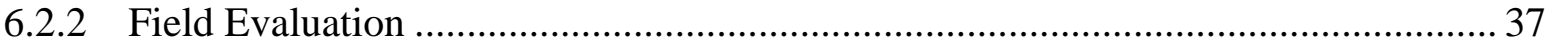

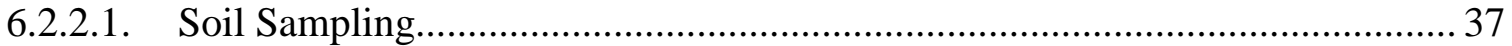

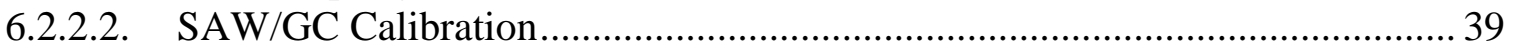

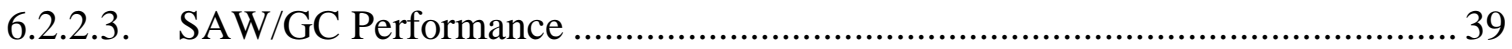

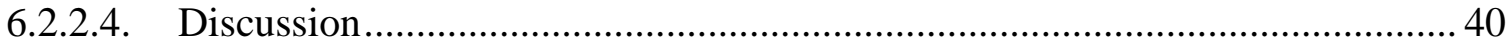

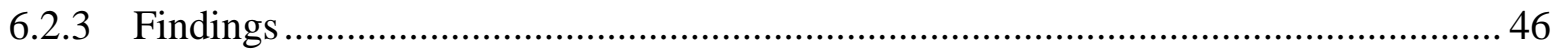

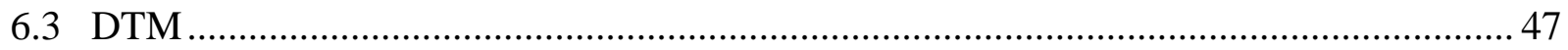

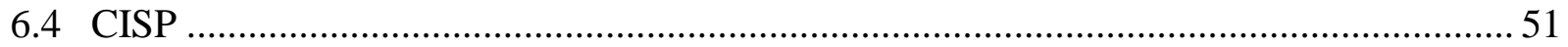

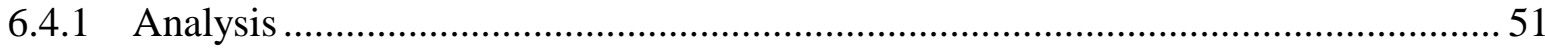

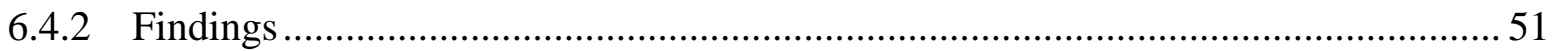

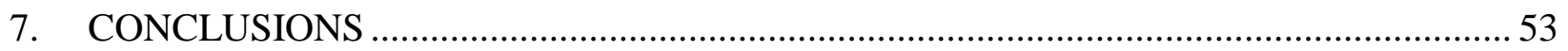

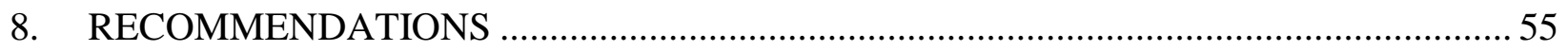

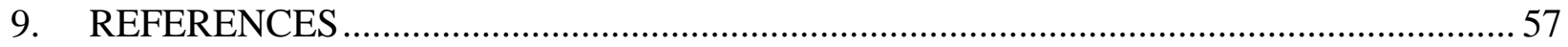




\section{FIGURES}

Figure

Page

Figure 1. Schematic of the DTD probe showing primary physical features. ...................................... 7

Figure 2. Schematic of the Modified Heated Transfer Line.............................................................. 10

Figure 3. Schematic of the CISP Probe showing the primary physical features................................. 12

Figure 4. Schematic of DTM showing primary internal components. .............................................. 16

Figure 5. Filter layering scheme used on the DTD and CISP ........................................................2 21

Figure 6. The sampling controls are housed in a field durable, weatherproof box designed to

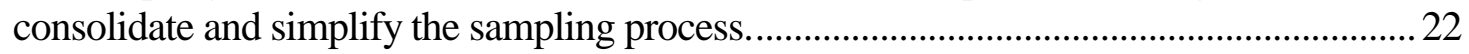

Figure 7. Thermoelectrically cooled SAW detector crystal. ...........................................................25

Figure 8. GC/SAW nozzle interface showing interaction of column and acoustic cavity..................26

Figure 9. Schematic of GC/SAW System showing major elements of the system............................ 27

Figure 10. Temperature Profiles from the DTD Probe Measured at the Probe and at Two Radial

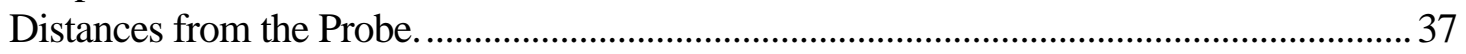

Figure 11. Chromatogram resulting from the soil-gas sample collected at 1.9 feet bgs.......................4 41

Figure 12. Chromatogram resulting from the soil-gas sample collected at 4.5 feet bgs....................... 42

Figure 13. Chromatogram resulting from soil-gas sample collected at of 6.0 feet bgs........................ 42

Figure 14. Chromatogram resulting from soil-gas sample collected at 8.6-feet bgs with ethylbenzene and m- and p-xylene peak incorrectly identified as o-xylene due to retention time instability.

Figure 15. This chromatogram shows the results from a sample collected from a depth of 10.5feet below grade..

Figure 16. Chromatogram of soil-gas sample from 8.6 feet bgs, overlain by chromatogram from instrument nitrogen blank showing carryover equivalent to $4 \mathrm{ppm}$ xylene.

Figure 17 Comparison of DTM analytical results for BTEX with bulk soil analytical results from both the present investigation and the baseline characterization

Figure 18 Comparison of DTM analytical results for TCE with bulk soil analytical results from both the present investigation and the baseline characterization

Figure 19 Comparison of DTM analytical results for PCE with bulk soil analytical results from both the present investigation and the baseline characterization ....

Figure 20. Suggested solution to the filter-clogging phenomenon, while still ensuring against cross- sample carryover. 


\section{INTRODUCTION}

The U.S. Department of Energy (DOE), the Department of Defense (DOD) and commercial industries continue to seek faster, more accurate, and more cost effective methods to conduct environmental site assessments. Using conventional characterization and monitoring techniques, the decision process is slowed and costs soar during the characterization and cleanup of hazardous waste sites. Conventional soil and groundwater sampling procedures present many opportunities for loss of volatile organic compounds (VOC) by exposing sample media to the atmosphere during transfers between sampling devices and containers, ultimately affecting the quality of the analytical results. Inaccurate characterization data leads to improperly designed remedial systems that slow the clean-up process and increase the cost. In situ methods for sample extraction and real time analysis provide attractive alternatives to conventional sampling and analysis.

To address these problems, DOE's Morgantown Energy Technology Center (METC) previously funded Applied Research Associates, Inc. (ARA) to develop a set of CPT-deployed sensors capable of measuring the level of volatile organic compound (VOC) and semi-volatile VOC contamination in situ. As a follow-on to that project, ARA has refined the sensors and associated equipment, and added the capability of detecting and measuring the level of halogenated VOCs. 


\section{OBJECTIVE}

The objective of this project is to further the development of a system of sampling probes for in situ detection and quantification of fuel and chlorinated hydrocarbon contamination present in subsurface soils using cone penetrometer testing (CPT) and high speed gas chromatography (HSGC) techniques. The improvements center around adapting the system to detect chlorinated solvents using a HSGC with a Surface Acoustical Wave (SAW) detector. The SAW/GC can perform rapid quantification for detection limits in the tens to hundreds of ppb range for many chlorinated compounds. Other improvements include improved filtering material for the in situ purge device as well as the addition of different transfer line materials for the chlorinated solvents. 


\section{TECHNICAL APPROACH}

Under a previous contract with METC, ARA developed a system of sampling probes for in situ detection and quantification of VOCs present in subsurface soils using cone penetrometer testing (CPT) and high speed gas chromatography (GC) techniques. During the course of this current project, ARA refined the previously developed downhole tools and uphole controls, and expanded their utility to detect and quantify halogenated volatile organic compounds in situ. Several key items were the focus of this project:

- The transfer line used to convey contaminated vapors to the gas chromatograph was reevaluated for use with chlorinated solvents,

- For saturated soils, an improved filter design was constructed and has been incorporated into the in situ purge device in an attempt to prevent clogging of the filter media during penetration of fine grained soils,

- The up-hole controls used to activate the downhole traps have been repackaged into a durable, field-portable case for improved ease of use,

- A commercially available, field portable, Surface Acoustical Wave/Gas Chromatograph (SAW/GC) developed by Electronic Sensors Technology (EST; formerly Amerasia) was incorporated as the analytical device used to identify and quantify the contaminants.

A separate module, the Down-Hole Trap module (DTM), was developed during the previous phase of this project to trap samples in the probe for subsequent laboratory analysis. During this phase of the project, the traps were exchanged for traps that are better suited to collecting both HVOC and VOC compounds. Using organic traps as opposed to Tedlar® bags provides better stability for the contaminants, thus reducing potential losses and increasing holding times. The DTM module can be equipped with several of these traps, such that several depth intervals in the same location can be sampled during a single push.

A soil-heating CPT sampling probe, the Dynamic Thermal Desorption (DTD) probe, also developed during the previous phase of this contract, was developed to liberate organic contaminants from subsurface soils by thermal desorption and convey them to the surface via a 
heated transfer line for analysis by HSGC. During the current project the filter material was improved and tested.

A down-hole purge system for ground water, the In Situ Purging (CISP) Probe, also developed previously, allows a controlled volume of groundwater to enter a sample chamber where it is subsequently purged with an inert gas to release contaminants. The liberated contaminants can be conveyed up-hole for analysis by HSGC or trapped down-hole using the DTM. During the current phase, a new filter approach was utilized in an attempt to reduce the tendency to clog in fine-grained soils.

The HSGC instrument and methods were selected to optimize fast, efficient speciation of BTEX compounds (benzene, toluene, ethyl benzene, and xylene), and several chlorinated compounds including tetrachloroethylene (PCE), trichloroethylene (TCE), cis 1,2dichloroethylene (1,2-DCE), and 1,1,1-tricloroethane (1,1,1-TCA). These compounds are typical of the contaminants commonly found on DoE and DoD facilities. The HSGC achieves speciation of these compounds in less than 15-seconds using a Surface Acoustic Wave (SAW) detector. 


\section{CPT SAMPLING EQUIPMENT DEVELOPMENT}

\subsection{DTD Probe}

\subsubsection{Principle of Operation}

The DTD probe draws a continuous gas sample from the interstices of soil in the unsaturated zone as the probe advances. The probe's soil heating function effects desorption of volatile organic compounds from the soil into the sampled gas thus increasing the concentration of volatiles in the sampled gas helping the system achieve lower detection limits for a given sampling duration.

A nonionic organic compound in the unsaturated zone will partition among four phases: pure phase, solute in water (aqueous phase), soil (adsorbed phase), and air (gas phase). The equilibrium distribution of an organic compound into the four phases depends on system pressure and temperature, thermodynamic properties of the compound, soil chemistry, and the presence of other compounds in the system. If the bulk concentration of the compound present does not exceed the saturated capacity of the matrix, then the pure phase may not be present.

For equilibrium between the solute gas phase and dissolved phase of a compound at low concentrations, Henry's Law is often applied:

$$
C_{w}=\frac{P_{i}}{H}
$$

where $C_{w}$ is the concentration of the solute in water on a molar basis $\left(\mathrm{mol} / \mathrm{m}^{3}\right), P_{i}$ is the partial pressure of the compound in the gas phase (atm), and $H$ is the compound's Henry's law constant (atm- $\mathrm{m}^{3} / \mathrm{mol}$ ). The Henry's law constant can be calculated using the pure vapor pressure $P^{0}$ and solubility $C^{S}$ of the solute in the expression $H=P^{0} / C^{S}$. Thus, the influence of temperature on vapor pressure and solubility will affect the equilibrium phase distribution between gas and aqueous phases.

To evaluate the effect of heating on the solute/vapor phase equilibrium distribution, consider that the variation of vapor pressure with temperature is described by the ClausiusClapeyron equation, using the compound's latent heat of vaporization, $\Delta H^{\text {vap }}$, and the universal Gas-law Constant, $R$, as follows: 


$$
P^{0}=P_{*}^{0} e^{\frac{\Delta H^{\text {vap }}}{R}\left(\frac{1}{T_{0}}-\frac{1}{T}\right)}
$$

where the * subscript indicates an arbitrary reference temperature. The Clausius-Clapeyron equation clearly indicates that saturation vapor pressure increases strongly with increasing temperature.

Solubility as a function of temperature has been approximated by a smoothing equation of the form:

$$
\ln C^{S}=A+\frac{B}{T}+C \ln T
$$

which, for positive values of the coefficients $B$ and $C$, can be shown to result in decreasing solubility with increasing temperature, which is an expression of variation in the solute activity in aqueous solution due to temperature. Thus, we can anticipate a shift of the equilibrium phase distribution of an organic solute toward greater gas phase concentration and lower aqueous phase concentration when the temperature of the system is increased.

For equilibrium partitioning between the adsorbed and solute phases, if the isotherm is linear, a partitioning distribution coefficient is usually applied:

$$
q=K_{d} C_{e q}
$$

where $q$ is the adsorbed phase concentration (mass basis), $K_{d}$ is the distribution coefficient, and $C_{e q}$ the liquid phase (solute) equilibrium concentration.

The distribution coefficient is correlated to the fraction of organic carbon $f_{o c}$ in the soil by use of an organic carbon partition coefficient, $K_{o c}$, and expressed as $K_{d}=K_{o c} f_{o c}$. Although we may estimate the temperature dependence of the distribution coefficient for halogenated organic solutes from solubility-temperature data by direct proportionality, we do not know the relationship for BTEX compounds. However, sorbed/gaseous phase partitioning equilibrium should be strongly dependent on temperature in the same manner as the aqueous/gaseous phase distribution due to the influence of temperature on the vapor pressure. 
Since phase partitioning relationships are temperature-dependent, with an apparent tendency toward greater gaseous phase concentration with increasing temperature, the heating sampling probe is designed to increase the concentration of contaminants in the vapor phase by increasing the temperature of the unsaturated soil matrix.

\subsubsection{DTD Probe Design}

A schematic of the DTD probe is shown in Figure 1. The primary physical features of the DTD probe are the heating sleeve and the sampling port. As the probe advances through the ground, the heating sleeve heats the soil matrix ahead of the sampling port to increase the proportion of VOC contamination residing in the vapor phase. By elevating the temperature of the matrix, the equilibrium partitioning distribution changes. This causes an increase in gaseous phase (volatilized) concentrations and a decrease in solid phase (adsorbed) and liquid phase (dissolved) concentrations. Soil gas is continuously drawn into the probe through the sampling port and transferred under slight vacuum to the surface for introduction to the HSGC. The transfer lines are heated to prevent sampled vapors from condensing before they reach the HSGC inlet.

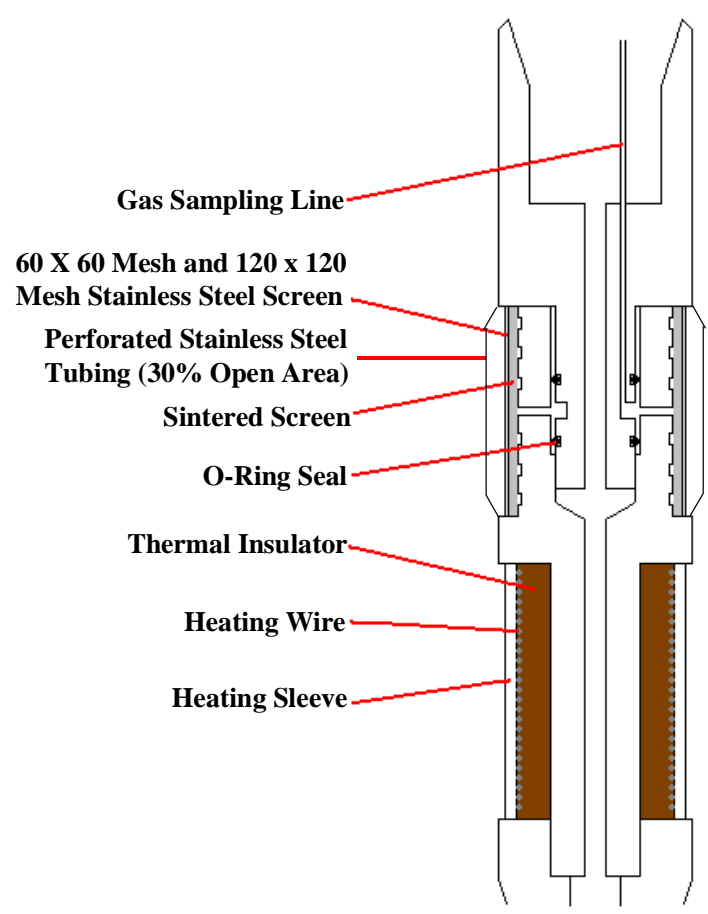

Figure 1. Schematic of the DTD probe showing primary physical features. The heating sleeve travels ahead of the sampling port and is maximized in length to promote a long soil contact time and the most uniform temperature distribution attainable in the effective sampling zone. 
The DTD probe was designed such that, for a given penetration rate, soil thermal characteristics, and power supplied to the heating sleeve, the maximum temperature of internal probe components will not reach damaging levels, while supplying as much heat as possible to the soil. These considerations influenced the probe geometry and construction materials.

To achieve maximum heat transfer at the soil/probe interface for a given penetration rate, the CPT cone was given the longest heating surface possible without sacrificing strength or elevating internal probe temperatures to damaging levels. The long heating surface maximizes contact time with the soil. As the probe advances, the power supplied to the heating sleeve is dissipated by thermal transfer into both the soil matrix and the rest of the probe. Heat transferred into the probe also dissipates axially along the probe and is subsequently transferred into the soil through contact ahead of and behind the heating sleeve. This axial heat conduction provides some cooling of the probe interior behind the heating sleeve.

\subsubsection{Heating Sleeve}

The heater is composed of an electrically resistive nickel chromium heating wire, wrapped around a glass-fused mica insulating arbor, and sheathed with a .080-in thick stainless steel heating sleeve which contacts the soil. Thermal heating coil is electrically insulated from the steel sleeve by a layer of moldable ceramic. The ceramic also increases thermal transfer efficiency between the coil and the sleeve, thus providing better thermal transfer to the soil.

\subsubsection{Sampling Port / Filter Design}

The probe sampling port was designed with both sampling performance and survivability in mind. During the previous phase of this project, problems were encountered with the filter material clogging. To resolve this the filtering scheme was modified to improve the performance of the sampler in fine grained soils. The sampling port is constructed of a solid manifold, wrapped by a porous stainless steel (sintered) filter and a series of protective screens. Details concerning the filter design are discussed in $\$ 4.5$. The manifold provides unencumbered flow along the whole length of and around the entire circumference of the interior surface of the filter. This arrangement promotes relatively uniform pressure gradient through the filter over its whole area. The sampling port length was kept relatively long to draw the sample gas from as close to 
the probe/soil interface as possible, where the maximum soil temperature, and thus maximum gaseous phase contaminant concentration, is achieved.

\subsubsection{DTD Probe Operation}

As the cone is advanced in depth, the heating sleeve heats soils through which the sampling port will pass. The heating sleeve operates on either 120-volt or 240-volt, single-phase $60 \mathrm{~Hz}$ AC power. Power is supplied to the heating sleeve from the surface via two 14-gage stranded copper conductors. A tri-ac at the surface is used to control the amount of power supplied to the heating sleeve. The sleeve temperature is monitored at the surface using a digital thermometer connected to a down-hole K type thermocouple embedded 0.020 inches from the resistive heating coil in the DTD probe.

A vacuum pump located downstream of the SAW/GC's sub-sampling line inlet creates the pressure gradient necessary to pull gas through the heated transfer line. The pump creates a 25-in $\mathrm{Hg}$ vacuum within the 150-foot transfer line. During the sub-sampling phase, a six-port, two-position sampling valve is used to isolate a sample loop, allowing the SAW/GC to draw from the sample loop, which is maintained at atmospheric pressure with ultra high purity nitrogen as a carrier gas.

The heated transfer line operates on 120-volt, single-phase $60 \mathrm{~Hz}$ AC power. Power to the self-regulating parallel resistance heat trace embedded in the transfer line bundle is controlled using a Variac. The transfer line temperature is monitored in the same manner as is the DTD probe heating sleeve temperature, with a $\mathrm{K}$ type thermocouple embedded at the mid-length in the transfer line bundle. Figure 2 illustrates a cross-sectional view of the new heated transfer line. 


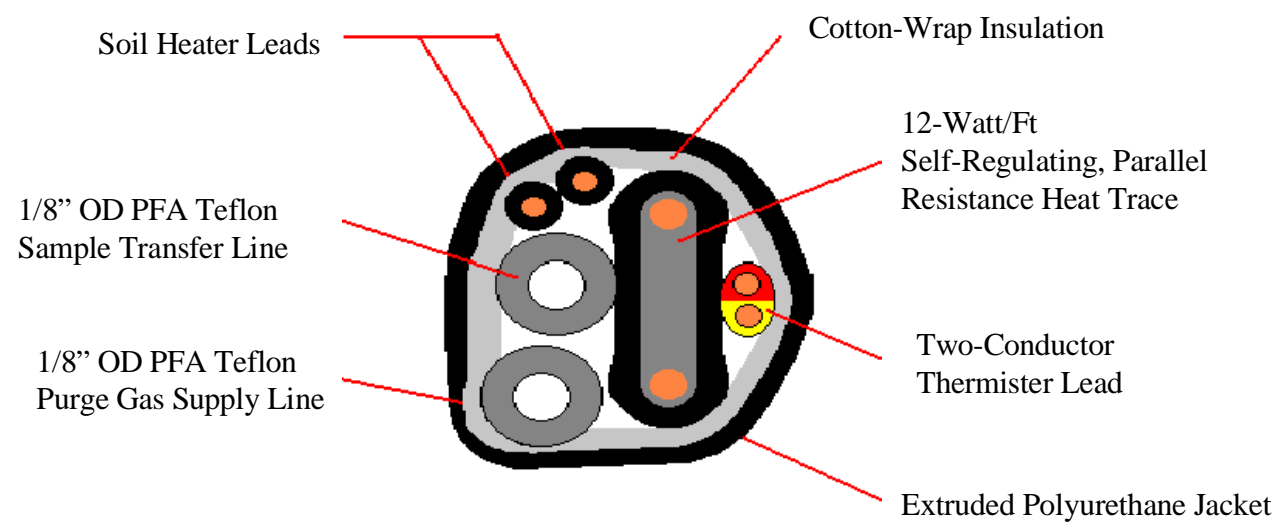

Figure 2. Schematic of the Modified Heated Transfer Line.

\subsection{CISP Probe}

\subsubsection{Principle of Operation}

Purge and trap methods enable the detection of many volatile organic compounds that are insoluble or slightly soluble in water. Generally, in this method an inert gas (nitrogen) is bubbled through a solution (groundwater) at ambient temperature so that the volatile organic compounds are efficiently transferred to the vapor phase.

Again, Henry's Law applies:

$$
C_{w}=\frac{P_{i}}{H}
$$

where $C_{w}$ is the concentration of the solute in water on a molar basis $\left(\mathrm{mol} / \mathrm{m}^{3}\right), P_{i}$ is the partial pressure of the compound in the gas phase (atm), and $H$ is the compound's Henry's law constant $\left(\mathrm{atm}-\mathrm{m}^{3} / \mathrm{mol}\right)$. As the purge gas, which initially contains no volatile organic compounds, is bubbled through the groundwater, volatile organic compounds in the groundwater are transferred to the purge gas as the system tends toward local partitioning equilibrium between the bubbles and the solution.

In ordinary laboratory practice, the vapor is then swept through an adsorbent column where it is temporarily adsorbed to the surface of the adsorbent material. Once purging is 
complete, the adsorbent column is heated and the trapped volatile organic compounds are flushed with an inert gas through a column to a gas chromatograph (GC).

The process described above has been integrated into the cone penetrometer system through development of the CISP probe. Groundwater is drawn into a purging chamber located down-hole in the CISP probe. The sample is purged and the vapor containing the inert gas and volatile contaminant is transported through a heated transfer line to the up-hole HSGC. Performing the purge in situ decreases the potential amount of sample loss frequently encountered in sample retrieval/laboratory analysis methods.

An alternative to direct analysis using the HSGC, the Down-hole Trap Module (DTM) can be used to retain the purged volatile organic compounds as in the conventional laboratory approach. The adsorbent column can be later retrieved from the DTM for desorption and analysis in a laboratory.

\subsubsection{CISP Probe Design}

A schematic of the CISP probe is shown in Figure 3. The primary features of the purging probe are the sampling system, the purging system, and the back-flushing system.

\subsubsection{Sampling System / Filter Design}

The groundwater sample taken into the CISP probe passes through two essential hardware components: multiple sample filtering components and a solenoid valve. As with the DTD, the sample filtering components were modified to enhance the ability to collect groundwater samples from fine-grained formations. The filters also help protect the solenoid valve from the damaging effects of fine soil particles, and keep soil particles from accumulating in the device where they may leach contaminants or foul internal surfaces. The filter design is discussed in greater detail in $\S 4.5$. 


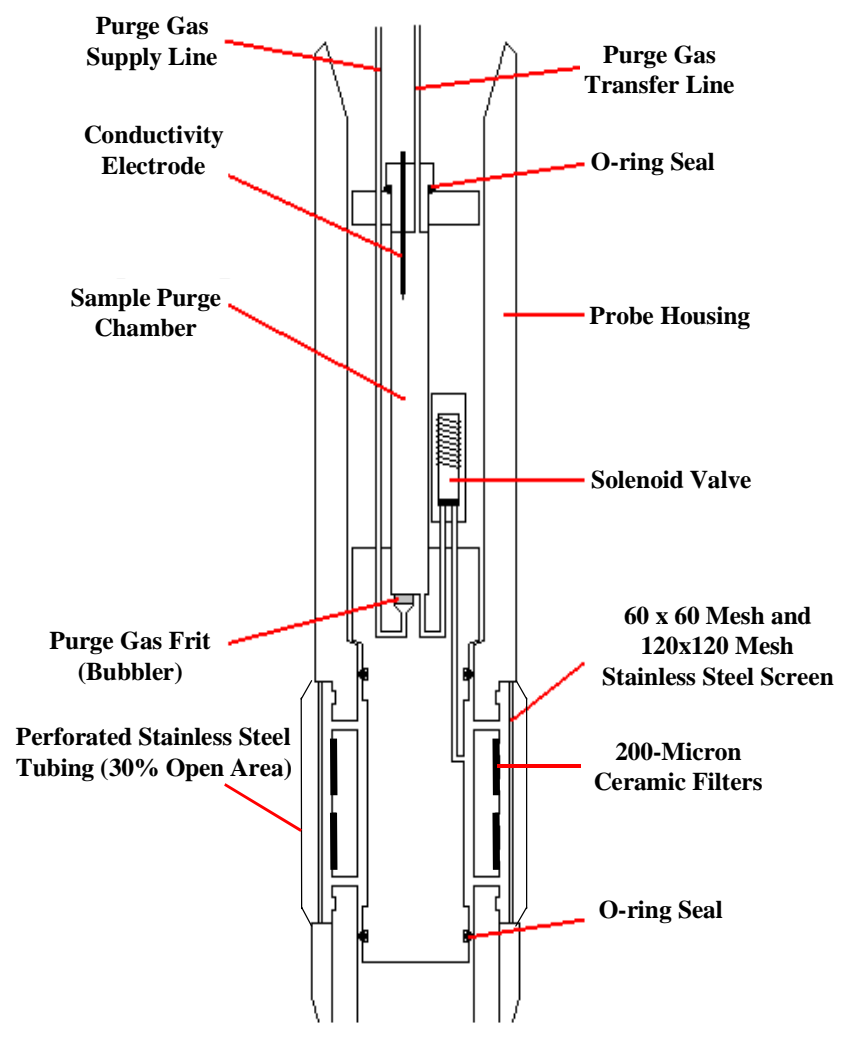

Figure 3. Schematic of the CISP Probe showing the primary physical features. A sample enters the sample/purge chamber through the slotted sleeve, sintered screen, and solenoid valve under hydrostatic pressure. The solenoid valve closes when the proper volume has entered as determined by the conductivity electrode. The sample in the chamber is purged with nitrogen bubbled through the purge gas frit. The stripped organics are carried to the surface via the heated purge gas transfer line, where they are analyzed by HSGC.

\subsubsection{Purge System}

Two concerns were addressed in the design of the purge system for the CISP probe. First, purge efficiency was considered. Studies have shown that purge efficiency (recovery) increases with increasing ration of headspace to sample volume in the purge chamber. A 2:1 ration was the greatest that could be achieved while suppressing surface bubble formation and keeping the probe length reasonable for field operations. Another factor affecting purge efficiency is the ratio of the surface area at the interface of the purge gas with the sample versus the volume of purge gas. Minimizing purge gas bubble size maximizes this ratio and thus, all other effects being equal, optimizes purge efficiency. The pore size of the purge gas frit was chosen to be 2 microns. This minimized bubble size while not requiring excessive pressure to operate and 
maintaining an essentially linear pressure vs. flow rate relationship to ease control of the purge process.

The second concern addressed in design of the purging mechanism was field serviceability, or the minimization of potential downtime. The internal workings of the CISP probe were constructed of two pieces that join at the base of the sample chamber. This allows the purge gas frit and most sealing o-rings to become accessible for replacement by removing a single bolt holding the two halves together. The solenoid valve, which controls flow in and out of the sample chamber, is also accessible for service or replacement by removal of the same bolt. This design feature is essential to minimizing downtime in the field should components fail or become fouled.

\subsubsection{Backflushing System}

Once the analytes of interest have been purged from the groundwater sample and analyzed by the up-hole HSGC, the CISP probe is backflushed. Backflushing is achieved by forcing the purged groundwater sample back out into the formation through the solenoid valve and sample filtering components. Because the analytes of interest have been purged from the sample, the sample becomes a solvent for cleaning the components along the sampling/backflushing flow path in preparation for the next sample. Cleanliness of the sample chamber and transfer line is verified after backflushing by analyzing purge gas blown through the empty sample chamber with the solenoid valve closed. The solenoid valve remains closed while the probe is advanced to the next depth at which an analysis is desired.

\subsubsection{CISP Probe Operation}

The probe is advanced to the desired depth by normal CPT procedures. The offset in depth between the sampling screen and the probe tip is accounted for. Advancement of the probe is paused during analysis. The following six steps compose the operation sequence of the CISP probe. Their execution is described below.

1. Advancing the probe to the desired analysis depth,

2. Allowing the sample chamber to fill with groundwater,

3. Purging volatiles from the groundwater sample, 
4. Sub-sampling and analyzing the purge gas using the HSGC,

5. Draining and backflushing the sample chamber, and

6. Verifying the cleanliness of the purge mechanism.

With the probe at the desired analysis depth, the operator switches a three-position toggle switch on the up-hole control panel to the fill position. In this position, the power is supplied to the normally closed down-hole solenoid valve, opening it to allow water to enter the sample chamber under hydrostatic pressure (pressure in the chamber is atmospheric). With the switch in the fill position, however, power to the valve may be interrupted by tripping of the conductivity level sensor. A light emitting diode (LED) remains lit while the down-hole solenoid valve is open. A second LED indicates when the pre-set sample volume (5-ml) has entered the chamber and tripped the level sensor. With the switch in the fill position, both LEDs cannot be lit simultaneously (i.e., once the correct volume occupies the sample chamber, the valve closes). The time to fill is measured and recorded. As the sample chamber fills, backflow of water into the purge gas inlet at the base of the chamber is prevented by the stainless steel frit, whose pore size (2-microns) is too small to allow follow-through under the hydrostatic pressure created in the chamber ( $50 \mathrm{~mm} \mathrm{H}_{2} \mathrm{O}$ maximum).

As the sample chamber fills, the rate of inflow can be monitored up-hole on the gas flow meter, which is connected to the outlet of the heated transfer line. The gas flux out the up-hole end of transfer line equals the volumetric flow rate of water entering the sample chamber because the water is displacing gas in the chamber and sending it up the transfer line. The transfer line is open to the sample chamber at the top of the head space.

With the groundwater sample in the sample chamber, the three-position toggle switch is set to the neutral position. In this position, the solenoid valve remains closed regardless of the water level in the chamber. This prevents inadvertent opening of valve due to purge gas bubbles influencing the state of the level sensor. An uphole toggle valve in the purge gas supply line is then opened, allowing purge gas (ultra pure grade nitrogen) to bubble through the water sample. Accounting for the travel time of the purge gas through the transfer line, the High Speed GC enters sampling mode as the first of the purge gas arrives at the sub-sampling tee connection. 
When the HSGC has finished sub-sampling the purge gas from the transfer line, the operator backflushes the probe by first closing the furthest upstream toggle valve in the transfer line, then pressurizing the purge gas line to 30 psi greater than hydrostatic pressure outside the probe, and finally switching the three-position toggle to the drain position. In the drain position, the down-hole solenoid valve is powered to open and remains as such regardless of the state of the level sensing circuit. The two LEDs indicate the state of the solenoid valve and level sensor.

The probe is allowed to backflush for a period equal to at least two times the product of the fill time and the ratio of the external hydrostatic pressure to the excess internal pressure (30 psi). For example, if the chamber filled in 90 seconds at 20 psi external hydrostatic pressure, then the backflush time at 50 psi internal pressure (20 psi external plus 30 psi excess) would be two times 90 seconds, times the ratio of 20 psi to 30 psi, or 120 seconds. Because the water flushed back through the sample entry path has been purged of the contaminants of interest, this water becomes a solvent for cleaning contaminants from the probe's sample flow path as it is discharged back into the formation.

At the end of the backflush period, the three-position toggle switch is set back to the neutral position, the purge gas supply is toggled off and set back to its purge mode pressure, and the transfer line toggle valve is opened, relieving the pressure in the lines and sample chamber.

Following a backflush, the cleanliness of the purge chamber can be checked prior to the next analysis by analyzing purge gas blown through the empty sample chamber. 


\subsection{DTM Probe}

\subsubsection{Trap Selection}

The DTM was designed to accommodate off-the-shelf geometry for the traps, both to maximize the variety of adsorbent materials available for use (thus maximizing the range of contaminants that can be trapped), and to make it convenient for analytical laboratories to handle the samples. A straight eight-inch diameter tube trap geometry was chosen because of its wide availability and its ability to fit within the spatial constraints the CPT deployment system. When coupled with solenoid valves for trap selection, a total of three traps could be located in the CPT rods as shown in Figure 4. Since the focus of this project concerned the detection of chlorinated compounds, VOCARB 3000 (Supelco Inc., Bellefonte, PA) tubes were used. They contain a combination of Carbopack B, Carboxen 1000, and Carboxen 1001 adsorbents. These traps were chosen because it is designed for capturing a wide range of VOC and HVOC compounds, for which the HSGC was optimized.

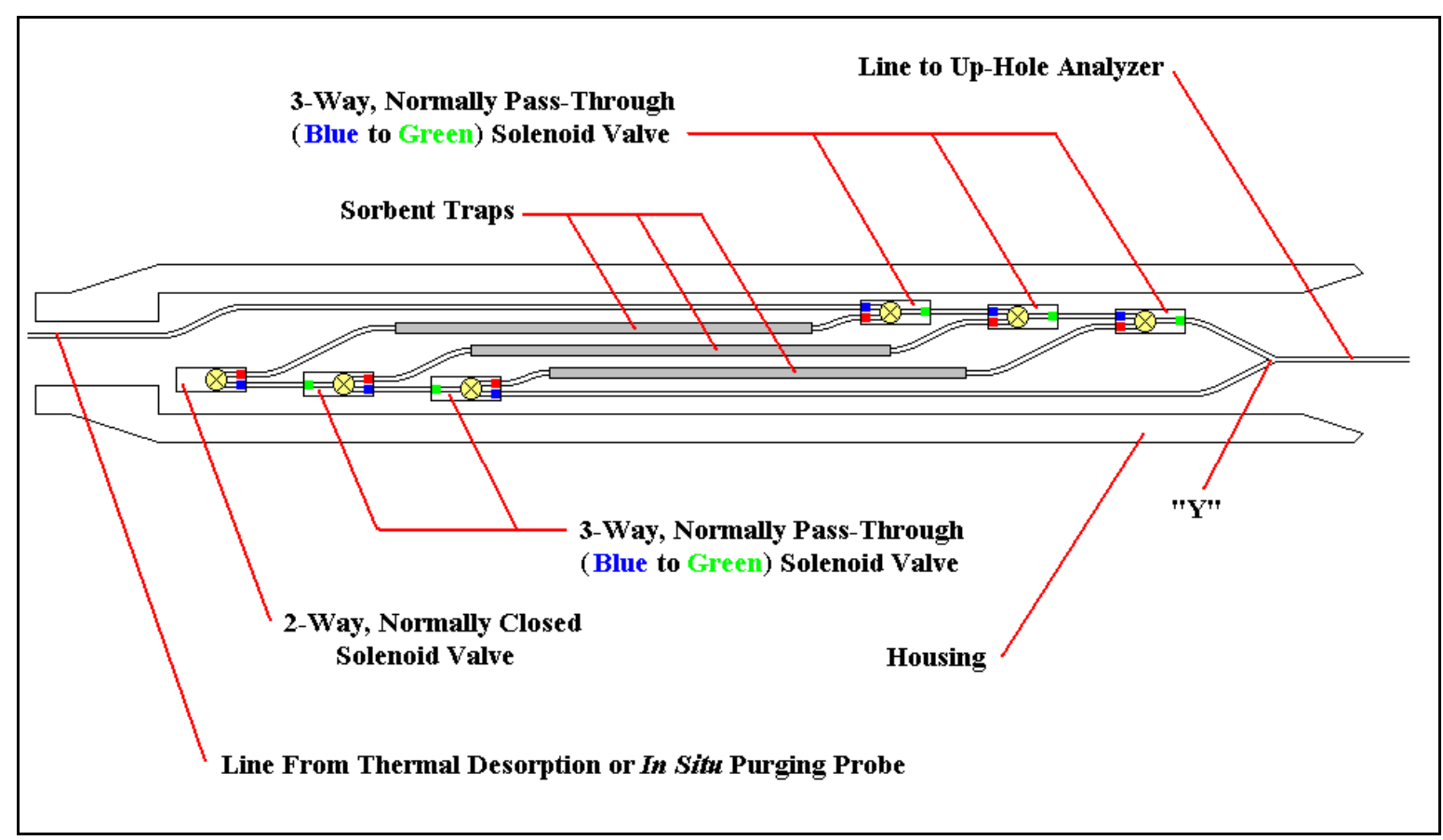

Figure 4. Schematic of DTM showing primary internal components. Sample or purge gas from the DTD or CISP probe enters the DTM at the left end and can be diverted through any of the three adsorbent traps or passed straight through under up-hole operator control. 3-way solenoid valves are actuated in pairs to control the flow path. The off-the-shelf traps are selected based on the volatile organic analyte(s) of interest. They are recovered between CPT penetrations for desorption and analysis in a laboratory. 


\subsection{Heated Transfer Line Development \& Testing}

\subsubsection{Teflon Tubing Transfer Efficiency Comparison}

Laboratory testing was conducted to compare the transfer efficiencies of two types of Teflon tubing to be used as a heated transfer line for CISP and DTD probes. Teflon ${ }^{\circledR}$ PFA (perfluoroalkoxy) and Teflon ${ }^{\circledR}$ FEP (fluorinated ethylene polypropylene) were the two tubings selected for the comparison. The goal of the testing was to determine which of the two tubings had less adsorption and carry-over of both halogenated and aromatic VOC's. The selected tubing was used as the heated transfer lines to transport volatile organic compounds (VOC's) from the down-hole sampling probe to an up-hole Surface Acoustical Wave/Gas Chromatograph (SAW/GC).

\subsubsection{Experimental Procedures}

\subsection{Tubing Preparation and Baseline Sample Collection}

Samples of both tubings were cleaned prior to testing by baking them in an oven at $110^{\circ} \mathrm{C}$ while flushing with Ultra High Purity (UHP) helium for two hours. Baseline samples were collected by flushing each of the Teflon ${ }^{\circledR}$ lines with 700-ml's of zero-grade air at a flowrate of $50-\mathrm{ml} \mathrm{min}^{-1}$. These samples were collected on Tenax $\mathrm{TA}^{\circledR}$ adsorbent tubes and were analyzed in accordance with a modified EPA Method TO-1 for the target analytes which include: tetrachloroethylene (PCE), trichloroethylene (TCE), toluene and $m$-xylene. Baseline samples were collected at both ambient $\left(25^{\circ} \mathrm{C}\right)$ and at elevated $\left(110^{\circ} \mathrm{C}\right)$ temperatures. The results of these sample analyses will be used to evaluate the level of residual target analytes emanating from the tubings resulting from the manufacturing process or environmental exposure.

\subsection{Target Analyte Mixture Preparation}

\subsection{Concentrated Mixture}

Concentrated gaseous standards were prepared in a static dilution bottle (SDB) using a technique developed by the EPA for air analysis (U.S. EPA, 1988). First, an equimolar mixture of neat target analytes, referred to as 'soup,' was prepared by injecting the appropriate volume of each target analyte into a 4-ml vial. By injecting a known volume of the 'soup' through the Mininert ${ }^{\circledR}$ valve into the SDB and allowing it to vaporize/equilibrate, a known concentration 
mixture of the target analytes was prepared. With a nominal volume of 2-Liters in the SDB, 17.2- $\mu \mathrm{L}$ of 'soup' was injected to produce a 500-ppm concentrated gaseous mixture of target analytes.

\subsection{Diluted Mixture}

To make the diluted mixture of the target analytes, 4-ml's of the concentrated gaseous mixture was withdrawn from the static dilution vessel with a gas-tight syringe and transferred to a 25-liter Teflon ${ }^{\circledR}$ bag that was thoroughly purged, evacuated, and filled with 20-L's of zerograde air. The result was 20 liters of target analyte mixture at a concentration of approximately $100 \mathrm{ppb}$. The precise concentration can be determined from the following expression:

$$
C_{\text {finial }}=\frac{C_{\text {initial }} \bullet V_{\text {initial }}}{V_{\text {final }}}
$$

where:

$C_{\text {final }}=$ Final concentration after dilution, $\mathrm{ppb}$

$C_{\text {initial }}=$ Initial concentration of alliquot collected from concentrated sample, $\mathrm{ppb}$

$V_{\text {initial }}=$ Volume of alliquot of concentrated sample, $\mathrm{ml}$

$V_{\text {final }}=$ Volume of alliquot plus dilutant, $\mathrm{ml}$

\subsection{Sample Collection}

\subsection{Initial Concentration Samples}

The precise concentration of the target analytes generated above was confirmed by Gas Chromatographic (GC) analysis of the Tenax ${ }^{\circledR}$ tube samples collected directly from the Tedlar ${ }^{\circledR}$ sampling bag. Samples were collected in triplicate to provide a statistical basis for determining the initial concentration.

\subsection{Ambient Temperature}

Immediately following the collection of the initial concentration samples, each of the coiled Teflon ${ }^{\circledR}$ transfer lines was attached directly to the Tedlar $^{\circledR}$ sampling bag and three individual $700 \mathrm{ml}$ aliquots of target analyte gas mixture were drawn through them at a flow rate of $50 \mathrm{ml} \mathrm{min}$. The flowrate was measured using a calibrated rotometer and the vacuum source was generated using an Air Cadet ${ }^{\circledR}$ single head, dry (oil-less) vacuum pump. Each aliquot was collected separately on a Tenax ${ }^{\circledR}$ tube. 
Each line was then purged with one 700-ml aliquot of zero-grade air to flush out any remaining remnants of the diluted target analyte gas mixture. The transfer efficiency was defined as the total mass transferred through the tubing in the three volumes of diluted gas standard plus the $700-\mathrm{mL}$ volume of purge air.

\subsection{Elevated Temperature}

Once the test series was completed at ambient temperature, it was repeated at an elevated temperature. The tubing was placed inside a laboratory-grade oven capable of maintaining a constant $110 \pm 0.5^{\circ} \mathrm{C}$ and the experiment was repeated.

\subsection{Sample Handling and Chemical Analysis}

Once the samples were collected they were quickly capped and sealed then placed inside individual glass vials sealed with Teflon seals. All samples were stored in a freezer and hand carried to Sci-Test, Inc. within 24-hours of collection for analysis. There they were analyzed in accordance with a modified Method TO-1 using a thermal desorption technique interfaced with a high-resolution gas chromatograph (GC). The GC is equipped with both a Hall detector and a PID connected in series. The results were presented in units of $\mu \mathrm{g}$ and carefully reviewed for quality control by both the contracted laboratory and ARA. The results and analysis of the results are presented in Section 6 


\subsection{Filter Material Selection}

One of the objectives of this project is to try to improve the filter material on both the CISP and DTD probes. With the previous designs, problems with screen clogging were experienced when pushing through silty and clayey soil. During the course of this project, different screen/filter materials were researched in hopes of finding a solution to the clogging problem. One prospective filter material included the Bladon filter material evaluated by Argonne National Laboratory. Previous studies have found that this material interacts with some chlorinated compounds resulting in degradation into daughter compounds. Since the detection and quantification of chlorinated compounds such as TCE and PCE are important for the project and remediation design, the use of Bladon filter material, which degrades these compounds, is inappropriate and will not permit the project objectives to be reached.

The most promising solution was a wellscreen material developed for the oil industry called Pall Stratapac ${ }^{\circledR}$ Screen developed by Pall Well Technology, Glen Cove, New York. The material consists of several concentric fine-mesh screens embedded with a sintered material to control fines, such as clay, silt and very fine sand, supported both on the inside and outside by a perforated support cage. Unfortunately, the available stock sizes did not meet our needs and the manufacturer was not able to produce limited quantities economically.

Since we were unable to locate a commercially available filter system, we elected to design and fabricate our own. Two different designs were selected for the DTD and CISP probes, respectively. For the DTD, the outermost sleeve consists of a length of perforated stainless steel tubing with an open area of approximately $30 \%$. This is followed by a series of fine mesh stainless steel screens used as secondary filters followed by a 100-micron sintered stainless steel filter. The perforated sleeve protects the inner screens and sintered filter from damage due to penetration stresses. The sintered filter keeps fine debris from clogging the gas sampling manifold located behind the filter.

A slightly different approach was used for the filter material on the CISP. The outermost sleeve consists of a length of perforated stainless steel tubing with an open area of approximately $30 \%$. This is followed by a series of fine mesh stainless steel screens used as secondary filters followed by a 200-micron porous ceramic filter. The 200-micron ceramic filter was selected to minimize the flow restriction that we experienced previously with the 100-micron sintered 
stainless steel. The perforated sleeve protects the inner screens and ceramic filter from damage due to penetration stresses. The ceramic acts as a final filter, protects the solenoid valve from the damaging effects of fine soil particles, and keeps soil particles from accumulating in the device where they may leach contaminants or foul internal surfaces. Figure 5 illustrates the layering of the various filter laminae used on the DTD and CISP, respectively.

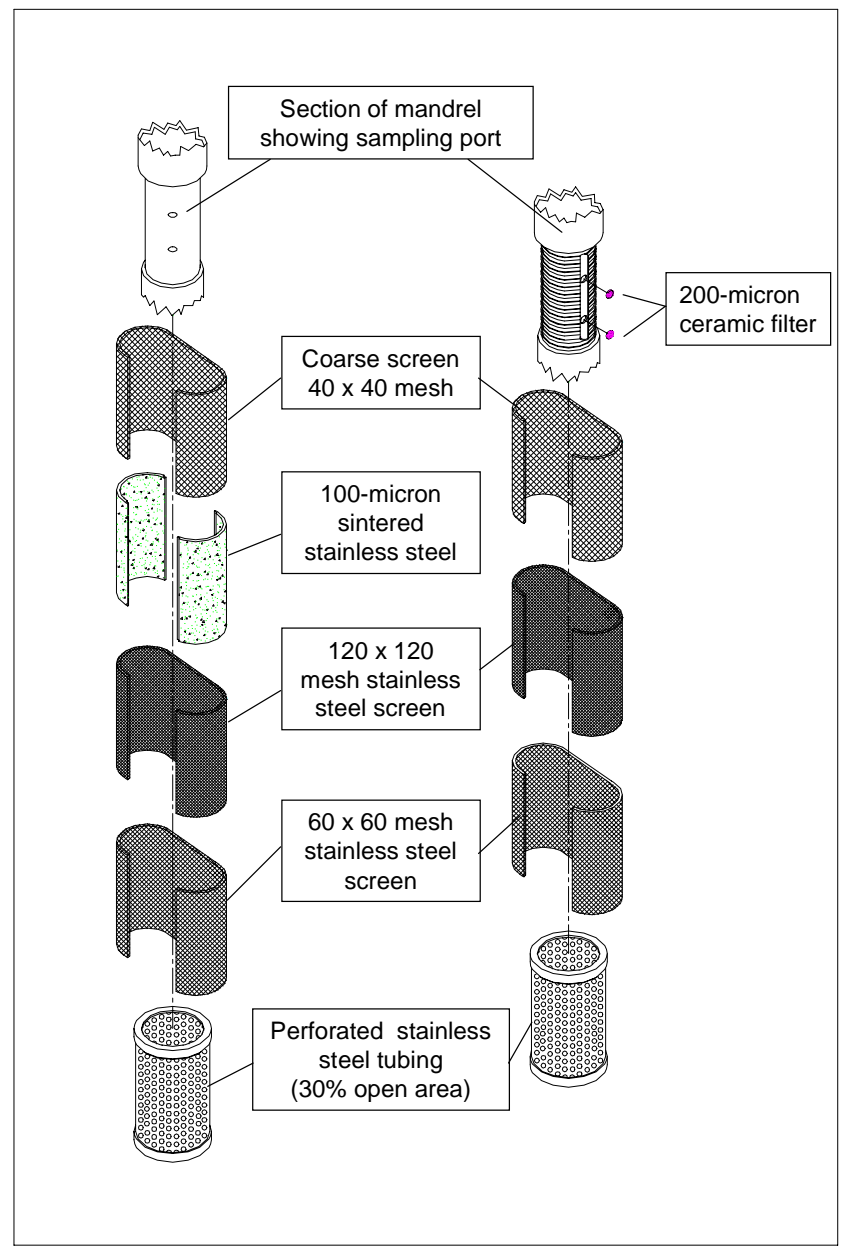

Figure 5. Filter layering scheme used on the DTD (left) and CISP (right).

\subsection{Control Panel}

One of the objectives of this project was to consolidate the electrical and pneumatic controls into a robust, field portable control box that would facilitate easy connection with, and operation of, the sensors. This was accomplished by housing all of the controls and pneumatic 
distribution systems in a durable weather-tight, Pelican ${ }^{\circledR}$ box. Figure 6 shows a photograph of the new control box.

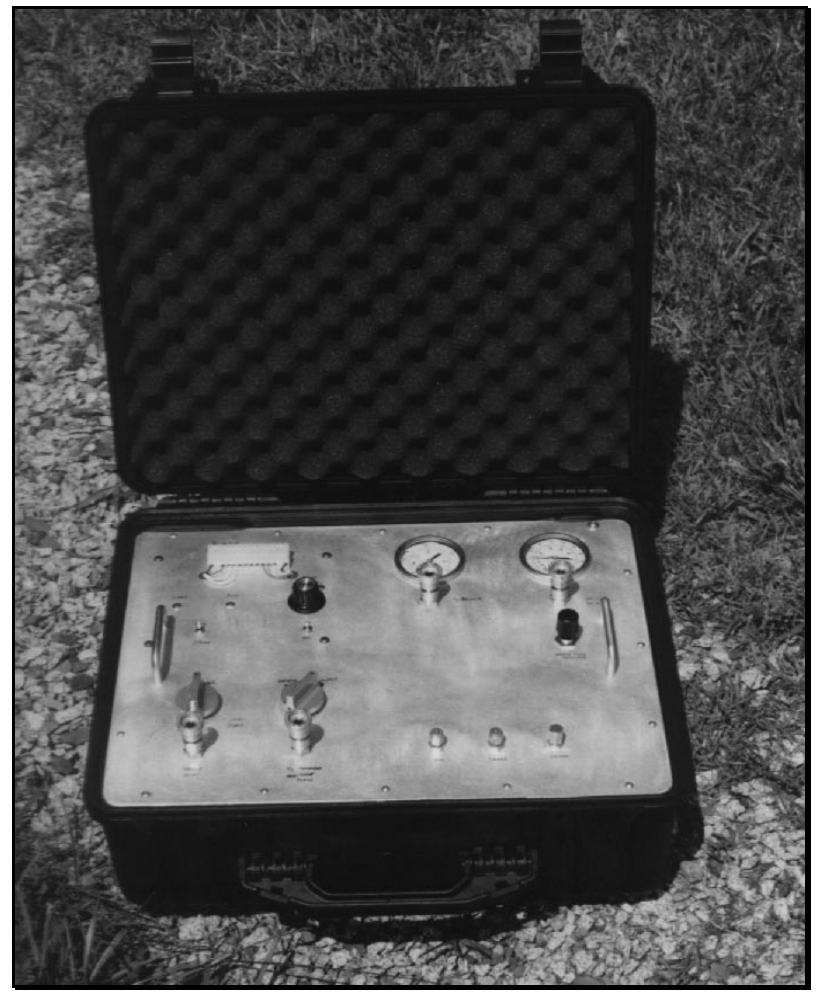

Figure 6. The sampling controls are housed in a field durable, weatherproof box designed to consolidate and simplify the sampling process.

The heart of the pneumatic distribution system consists of two Valco ChemInert ${ }^{\circledR}$ valves: a six-port stream selection valve and a six-port, two-position sampling valve. The stream selection valve allows the operator to select the vacuum source, nitrogen pressure source, or a vent, depending on the mode of operation. The sampling valve provides a means to isolate a discrete sample from the transfer line, which is under vacuum, permitting sub-sampling by the GC.

The control panel (Figure 6) also permits easy connections of the various pneumatic and electrical connections. Quick-connects are provided for the vacuum source as well as the nitrogen pressure source used for purging. Connections are also provided for the sample transfer line, the GC subsampling port, carrier gas, and a vent to the atmosphere. A wiring terminal block 
provides a simple and secure method to attach the control wires used to power the various solenoid valves in both the CISP and the DTM. 


\section{HIGH-SPEED GAS CHROMATOGRAPHY (HSGC)}

\subsection{Instrument Overview}

The instrument used for the detection and quantification of contaminants within the sampling stream was a field portable GC system equipped with a Surface Acoustic Wave (SAW) detector. This instrument was developed by Electronic Sensors Technology, Inc., Newbury Park, California. Unlike other types of GC detectors, the SAW detector is a temperature controlled integrating mass detector with zero retention volume and the ability to operate with chromatography peak widths measured in milliseconds. An internal sample pump and Tenax trap collect analyte vapors entrained within ambient inlet air. Speciation is accomplished using a short, temperature-ramped GC column selected for its ability to separate analytes of interest. Detecting the total amount of each analyte as it exits the column performs quantification. By focusing the effluent from the column onto a specific area within a surface acoustic wave resonance-field on the surface of a temperature controlled piezoelectric crystal, picogram sensitivity is achieved.

\subsection{SAW Detector Description}

A large amount of research has been performed with chemical coatings applied to SAW crystals. A common approach is to expose an array of SAW crystals with different polymer coatings to the vapor to be characterized. In theory, each polymer coating will adsorb the vapors differently and by comparing response patterns from the array of sensing crystals, identification can be accomplished. However, polymer coatings reduce the sensitivity of the SAW crystal and limit detection to nanogram levels. Further loss in sensitivity results because the vapor sample must be split between many sensing crystals. Polymer coatings are not highly specific, and in general, each coated crystal response overlaps the response of other crystals to some extent, and in this case, pattern recognition with non-orthogonal (overlapping) responses is very difficult.

A new type of SAW vapor detector with pictogram sensitivity, which does not use polymer coatings, has been developed (Staples et al., 1994). The sensing crystal comprises a very high Q SAW resonator placed in contact with a small thermoelectric cooling element as depicted in Figure 7. The thermoelectric element provides the precise control of cooling needed for vapor adsorption, and simultaneously, the ability to clean the crystal using thermal desorption when needed. 


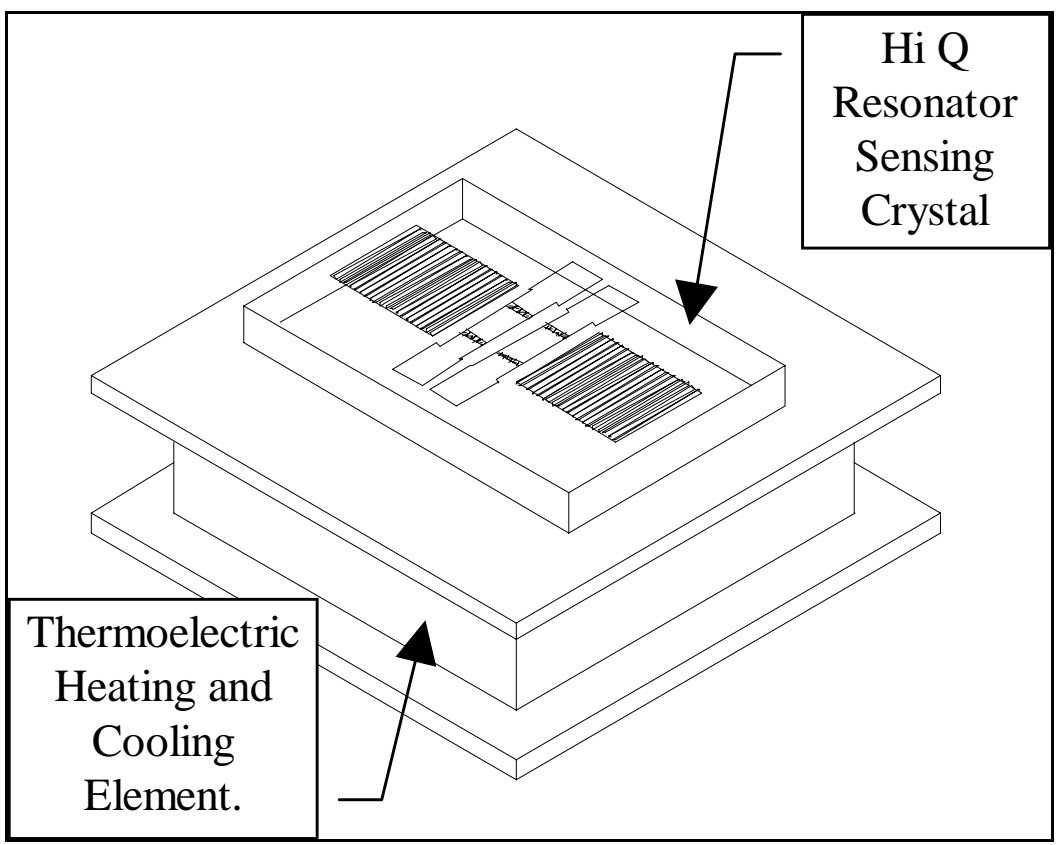

Figure 7. Thermoelectrically cooled SAW detector crystal.

The focused SAW resonator sensing element provides part per billion sensitivity for volatile organics and part per trillion sensitivity for semi-volatile compounds. The crystal operates by maintaining highly focused and resonant surface acoustic waves at $500 \mathrm{MHz}$ on the face of a single crystal quartz chip. By focusing the vapor through a micro-nozzle as shown in Figure 8, femtogram sensitivity can be achieved. This result (Staples and Watson, 1995) is 1000 times lower than SAW crystals coated with polymers. Because the crystal is manufactured from single crystal quartz without polymer coatings, long term stability and precision is achieved over a wide temperature range.

The SAW sensor only requires a low voltage power source and because it is non-ionic, does not require a radioactive ionization source. The ability to detect compounds based upon their ability to absorb onto a cooled surface provides detection capabilities that can be extended to an indefinite analyte list without regard to analyte polarity or electronegativity. 


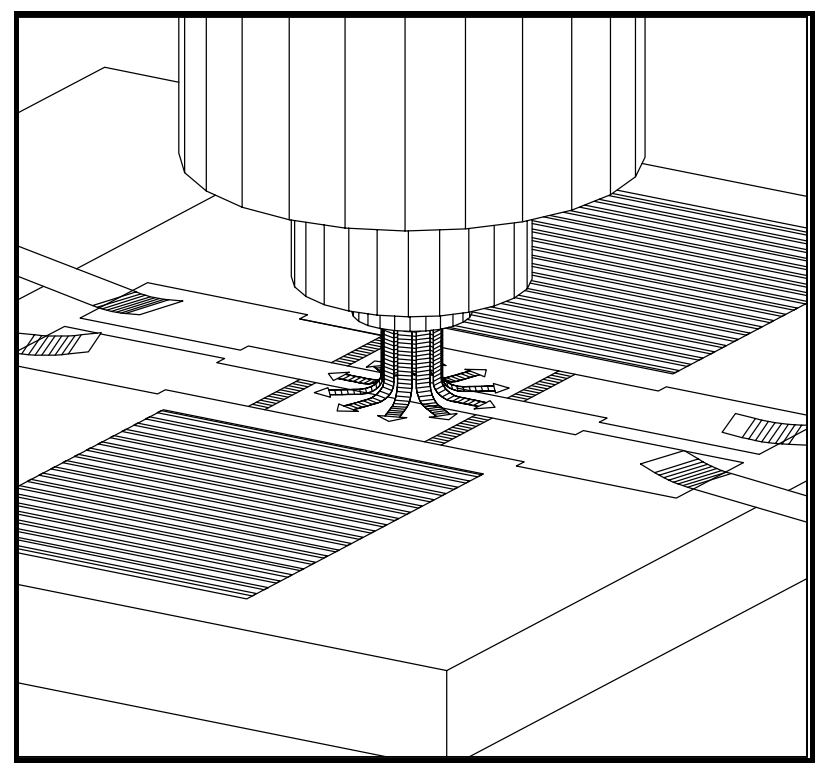

Figure 8. GC/SAW nozzle interface showing interaction of column and acoustic cavity.

The uncoated SAW detector is only specific to vapor pressure. The specificity of the uncoated SAW detector is based upon the temperature of the crystal surface and the vapor pressure characteristics of the condensate itself. At a given crystal temperature, only those analytes with dew points below the crystal temperature will condense and be detected. This provides a general method for separating volatile from non-volatile vapors based upon the selected operating temperature of the SAW crystal.

\subsection{GC/SAW Fast Chromatography System}

By combining SAW detectors with high speed temperature programmed chromatographic columns, specificity over a wide range of vapors at the part per billion level in near real time (10 seconds) has been achieved (Watson and Staples, 1990). The GC/SAW offers the advantages of a low cost solid state detector and the specificity of a temperature programmed GC column.

The major elements of a GC/SAW vapor detection system are shown in Figure 9. The analysis is performed in two steps corresponding to the two positions of the GC rotary valve. In the sample position (shown), air to be tested passes through an optional inlet filter and a loop trap. The trap contains absorbent specific to the desired analyte (e.g. Tenax). Selection of sample time and flow rate determines the total amount of airborne vapors collected in the loop trap. 


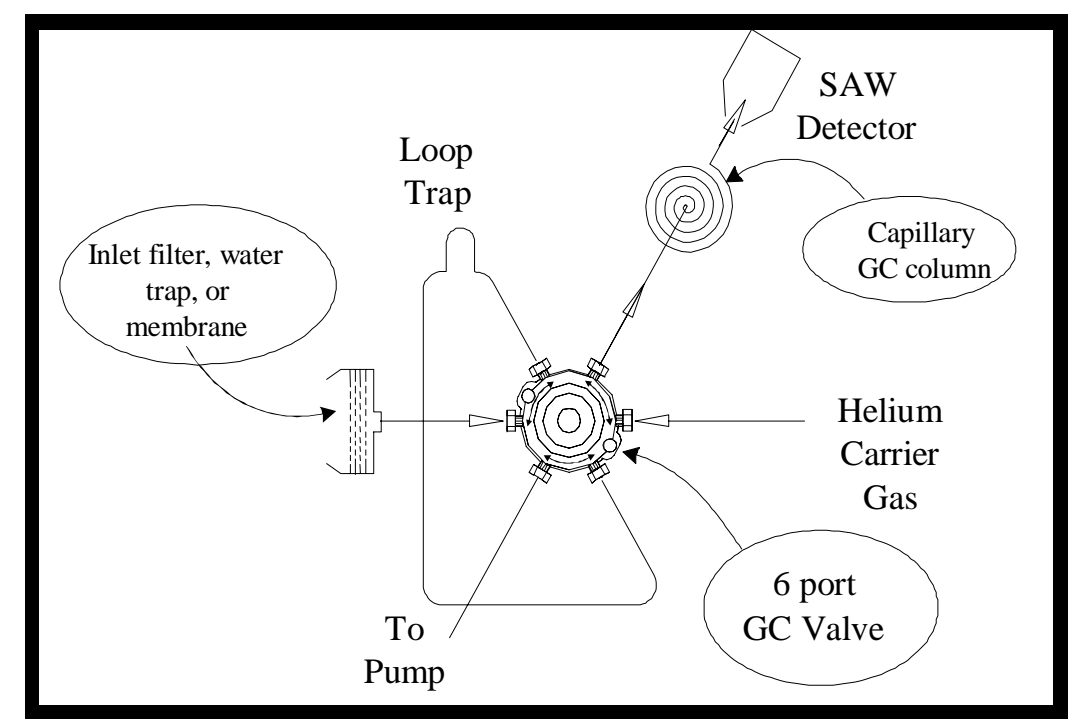

Figure 9. Schematic of GC/SAW System showing major elements of the system.

The GC valve is rotated to its second position and the loop trap is rapidly heated by a capacitive discharge, which causes trapped vapors to be transferred to the GC column. Transfer is aided by a helium carrier gas and these vapors re-condense on the inlet of a chromatographic column held initially at low temperature. A micro processor then applies a linear temperature ramped heating program to the GC column. The column separates the injected compounds in time, and as they are eluted from the column, they condense on the SAW crystal and are detected as frequency changes.

The speed of the analysis system is determined by the sample time and the analysis time. Typical sample times are 1 to 5 seconds and analysis times can be 10 seconds or less. Chromatographic peaks produced are measured in milliseconds. The ability to detect short duration peaks is made possible because the SAW detector is an integrating GC detector, which by definition has zero dead volume. All other known GC detectors are differential and because of dead volume within the detector cannot operate with millisecond duration chromatographic peaks.

The GC/SAW system is able to simultaneously detect and quantify multiple chemical vapors within a single environmental sample. The complete system is field portable and designed to fit within a small suitcase. A laptop computer provides a fully integrated user interface in a Windows 95 operating environment. An internal microprocessor, gate array 
controller, and a small helium gas tank are housed within the base of the suitcase. Field testing of prototype systems, using Surface Acoustic Wave sensors and chromatographic columns, has demonstrated the ability to detect a wide range of compounds including drugs, explosives, volatile organics, polychlorinated biphenyl, and dioxins (Watson, et al., 1991; US Patent No. $5,289,715$ ). Part per billion (picogram) sensitivity and field performance of this new technology has been validated by the Office of National Drug Control, the Department of Energy, and the U.S. Environmental Protection Agency (EPA-ETV).

\subsection{Method Development}

During a three-day training exercise at the EST facility in Newbury Park, California, ARA worked with EST's scientists and engineers to develop a method designed specifically for detecting a selected list of analytes including aromatic and halogenated hydrocarbons. Specifically, the compounds included:

- BTEX compounds,

- Tetrachloroethylene (PCE),

- Trichloroethylene (TCE),

- 1,1,1-Trichloroethane (1,1,1-TCA),

- cis 1,2-Dichloroethene (cis 1,2-DCE)

The method was designed for optimal separation of the target analytes, speed, and sensitivity. The method begins with a pre-sample pump time duration of 5 seconds to purge the transfer line between the sampling control box to the GC. Next, the sampling valve automatically switches to the sample position and the sampling pump runs for 10 seconds at a flow rate of $30 \mathrm{ml} / \mathrm{min}$. The valve then automatically switches to the inject position, fires the trap and begins to ramp the column temperature from 35 to $70^{\circ} \mathrm{C}$ at a rate of 5.5 degrees / second. Data is collected for 20 seconds at a rate of 20 milliseconds/point. Once the data is collected, the SAW is heated to approximately $130^{\circ} \mathrm{C}$ and allowed to bake for 15 -seconds to insure that any residual contaminants are removed from the SAW detector. The carrier gas flow rate for this method is approximately $3-\mathrm{ml} / \mathrm{min}$. 


\subsubsection{Calibration}

A one-point calibration scheme was used during the field-testing portion of this project. Beginning with certified standards from both Scott Specialty Gases (BTEX components), Matheson Gases, Inc. (cis 1,2-DCE, 1,1,1-TCA, and TCE), and neat PCE, dilutions were made to yield 10-ppm calibration standards. The PCE standards were made in accordance with the procedures described in (US EPA, 1988). Ultra-high purity (UHP) grade nitrogen was used as the dilution gas for all standards. Standards were made in dedicated 1-liter Tedlar ${ }^{\circledR}$ bags using appropriately sized gas-tight syringes. Fresh dilutions were made on a daily basis during field testing.

\subsubsection{Detection Limits}

An exhaustive detection limit study was not conducted as a part of this study. Detection limits of this instrument are compound specific and controlled studies have been conducted and published by the manufacturer. Table 1 lists the detection limits of the target analytes published by the manufacturer using a similar method.

Table 1. Detection Limits of Target Analytes.

\begin{tabular}{|l|c|}
\hline \multicolumn{1}{|c|}{ Target Analyte } & $\begin{array}{c}\text { Detection Limit } \\
\text { (ppm) }\end{array}$ \\
\hline cis 1,2-DCE & 0.110 \\
\hline $1,1,1-\mathrm{TCA}$ & 3.570 \\
\hline TCE & 0.040 \\
\hline PCE & 0.010 \\
\hline Benzene & 0.240 \\
\hline Toluene & .0019 \\
\hline Ethylbenzene & 0.002 \\
\hline m\&p Xylene & Not Reported \\
\hline o-Xylene & 0.002 \\
\hline
\end{tabular}




\section{RESULTS}

\subsection{Heated Transfer Line}

The laboratory testing of heated transfer line materials compared two types of Teflon ${ }^{\circledR}$ with regard to their impact on the transfer of selected gaseous volatile organic analytes due to adsorption and desorption of the analytes to and from the transfer line material. The two materials tested were PFA and FEP. These two materials were initially selected as the best candidates based on a literature review of similar studies. Interaction of the candidate materials with two chlorinated solvents, trichloroethene (TCE) and perchloroethene (PCE), and two aromatic hydrocarbons, toluene and m-xylene, was evaluated. Details of the testing procedure were discussed in Section 5.4.1.1.

\subsubsection{Chemical Analytical Results}

Laboratory analyses of the Tenax ${ }^{\circledR}$ traps were conducted by an independent commercial analytical laboratory. The results are summarized in Table 2. Results of duplicate sample analyses and quality control samples verify the analytical results shown are within the quality assurance objectives of the experiment. 
Table 2. Results from the Study Comparing Transfer Line Efficiency.

\begin{tabular}{|c|c|c|c|c|c|c|c|c|}
\hline \multirow[t]{2}{*}{ Tenax ID } & \multirow[t]{2}{*}{ Sample ID } & \multirow[t]{2}{*}{ Tubing } & \multirow[t]{2}{*}{ Environment } & \multirow{2}{*}{$\begin{array}{c}\text { Nominal } \boldsymbol{C}_{\circ} \\
p p b v / v\end{array}$} & \multicolumn{4}{|c|}{ Mass of Analytes $(\mu \mathrm{g})$} \\
\hline & & & & & $T C E$ & Toluene & $P C E$ & m-Xylene \\
\hline 8 & Initial Conc. & $\mathrm{N} / \mathrm{A}$ & Ambient & 100 & 0.38 & 0.33 & 0.41 & 0.25 \\
\hline 13 & Initial Conc. & $\mathrm{N} / \mathrm{A}$ & Ambient & 100 & 0.39 & 0.32 & 0.42 & 0.26 \\
\hline 16 & Initial Conc. & $\mathrm{N} / \mathrm{A}$ & Ambient & 100 & 0.37 & 0.25 & 0.41 & 0.23 \\
\hline 7 & Baseline & FEP & Ambient & 0 & $<0.02$ & 0.07 & $<0.02$ & $<0.02$ \\
\hline 17 & Final \#1 & FEP & Ambient & 100 & 0.36 & 0.34 & 0.45 & 0.3 \\
\hline 25 & Final \#2 & FEP & Ambient & 100 & 0.36 & 0.27 & 0.42 & 0.28 \\
\hline 24 & Final \#3 & FEP & Ambient & 100 & 0.37 & 0.28 & 0.44 & 0.29 \\
\hline 26 & Purge & FEP & Ambient & 0 & 0.02 & $<0.02$ & 0.03 & 0.02 \\
\hline 6 & Baseline & FEP & Elevated & 0 & $<0.02$ & 0.07 & $<0.02$ & $<0.02$ \\
\hline 10 & Final \#1 & FEP & Elevated & 100 & 0.36 & 0.27 & 0.43 & 0.27 \\
\hline 20 & Final \#2 & FEP & Elevated & 100 & 0.36 & 0.28 & 0.42 & 0.29 \\
\hline 15 & Final \#3 & FEP & Elevated & 100 & $\mathrm{~N} / \mathrm{A}$ & $\mathrm{N} / \mathrm{A}$ & $\mathrm{N} / \mathrm{A}$ & $\mathrm{N} / \mathrm{A}$ \\
\hline 14 & Purge & FEP & Elevated & 0 & $<0.02$ & $<0.02$ & $<0.02$ & $<0.02$ \\
\hline 19 & Baseline & PFA & Ambient & 0 & $<0.02$ & 0.03 & $<0.02$ & $<0.02$ \\
\hline 4 & Final \#1 & PFA & Ambient & 100 & 0.36 & 0.28 & 0.4 & 0.27 \\
\hline 11 & Final \#2 & PFA & Ambient & 100 & 0.38 & 0.3 & 0.44 & 0.29 \\
\hline 5 & Final \#3 & PFA & Ambient & 100 & 0.38 & 0.28 & 0.44 & 0.3 \\
\hline 1 & Purge & PFA & Ambient & 0 & 0.02 & 0.05 & 0.03 & 0.02 \\
\hline 18 & Baseline & PFA & Elevated & 0 & $<0.02$ & $<0.02$ & $<0.02$ & $<0.02$ \\
\hline 12 & Final \#1 & PFA & Elevated & 100 & 0.32 & 0.26 & 0.39 & 0.26 \\
\hline 9 & Final \#2 & PFA & Elevated & 100 & 0.44 & 0.39 & 0.48 & 0.32 \\
\hline 3 & Final \#3 & PFA & Elevated & 100 & 0.45 & 0.41 & 0.55 & 0.37 \\
\hline 2 & Purge & PFA & Elevated & 0 & 0.02 & 0.02 & 0.03 & 0.02 \\
\hline
\end{tabular}

\subsubsection{Method of Evaluation}

The analytical data from the transfer line efficiency evaluation were analyzed statistically by ARA to determine which material would be the most suitable for use as transfer line tube. The objectives were to evaluate (a) whether either tubing material significantly adsorbed the volatile organic analytes, and (b) whether there was a statistically significant difference between the performance of the two tubing materials in this regard.

The data were treated using a hypothesis test, which is a fundamental tool of Bayesian statistical modeling ${ }^{1}$. A hypothesis test is a way of mathematically determining whether a population of measurements of a random variable (represented by a sample from that

\footnotetext{
${ }^{1}$ Kufs, Charles, T. Statistical Modeling of Hydrogeologic Data - Part I: Regression and ANOVA Models, Groundwater Monitoring Review, Spring, 1992.
} 
population) overlaps a fixed value (or in this case, the distribution of measurements from the initial samples) sufficiently to be considered statistically different. Statistical tests typically begin with the hypothesis that there is no difference between the population in question and a fixed value (called a one-population test) or a second population (called a two-population test). This is called the null hypothesis $\left(\mathrm{H}_{0}\right)$. The alternative hypothesis $\left(\mathrm{H}_{\mathrm{A}}\right)$ is that there is a difference.

To conduct the hypothesis test we compared the difference between the mean of the initial concentration of the target compounds, collected directly from the source, to the mean of the samples collected after conveying the gas mixture through the respective tubings. This was done for both Teflon ${ }^{\circledR}$ PFA and FEP, at both ambient and elevated temperature conditions. If we state the null hypothesis to be that there is no difference in the means between the samples collected directly from the source and the samples collected after passing through the tubings, then the alternative hypothesis $\left(\mathrm{H}_{\mathrm{A}}\right)$, is that there is a difference. Mathematically this is stated as follows:

$\mathrm{H}_{0}: \mu_{1}-\mu_{2}=0$

$$
\mathrm{H}_{\mathrm{A}}: \mu_{1}-\mu_{2} \neq 0
$$

This is known as a two-tailed test because it examines both sides (tails) of the sample distribution.

The first step to perform this analysis is to determine estimators for the two population means by calculating the sample means:

$$
\begin{gathered}
\bar{Y}=\frac{\sum_{i} Y_{i}}{n_{1}} \\
\bar{Z}=\frac{\sum_{i} Z_{i}}{n_{2}}
\end{gathered}
$$


Where: $\bar{Y}$ and $\bar{Z}$ are estimators of the population means, and $n_{1}$ and $n_{2}$ are the number of individual samples.

Next we determine $s^{2}$, an estimator of the common variance $\sigma^{2}$ :

$$
s^{2}=\frac{\sum_{i}\left(Y_{i}-\bar{Y}\right)^{2}+\sum_{i}\left(Z_{i}-\bar{Z}\right)^{2}}{n_{1}+n_{2}-2}
$$

Where $s^{2}=$ best estimator of the common variance

Followed by an estimator of $\sigma^{2}(\bar{Y}-\bar{Z})$; the variance of the sampling distribution of $(\bar{Y}-\bar{Z})$ :

$$
s^{2}(\bar{Y}-\bar{Z})=s^{2}\left[\frac{1}{n_{1}}+\frac{1}{n_{2}}\right]
$$

Finally, the $t$-Statistic is calculated from:

$$
t=\frac{\bar{Y}-\bar{Z}}{s(\bar{Y}-\bar{Z})}
$$

This value is compared to the Students t-Distribution for a given degree of certainty with $n_{1}+n_{2}-2$ degrees of freedom. If the calculated value exceeds the tabulated value, the null hypothesis is rejected meaning there is a statistically significant chance that the sample collected from the source is different from the samples collected after drawing the gas mixture through the tubing. In other words, the tubing either retained or produced a mass of the target analytes.

\subsubsection{Discussion}

The statistical analyses of the analytical results indicate that neither tubing material significantly adsorbed the analytes of interest. However, the PFA tubing appears to perform slightly better than the FEP tubing in this regard. This is evident by analysis of the purge results between each test (i.e. the baseline row in the table) from each of the four tests. The elevated (heated ) PFA tubing was the only tubing test not to indicate any carryover 
contamination (i.e. all the baseline values were non-detects). All the other tests indicated some Toluene carryover or bake-out in the tubing.

The carryover, bake-out or adsorption can also be seen by analyzing the recoveries of each of the individual test sequences. These results are presented in Table 3. For the FEP tubing all the recoveries at both ambient and elevated temperature the recovery was within $10 \%$ of the target value except for three test. Each of these three exceptions only missed the $+/-10 \%$ range by $+/-1 \%$. The PFA tubing on the other hand had only two instances of where the recovery was not with the $+/-10 \%$ range of the target value. However for these two exceptions one was $1 \%$ but the other was $11 \%$ outside the acceptable range. The results on the elevated tubing with m-xylene are interesting and warrant additional analysis. For the FEP tubing, the highest purge contaminant was 0.03 , as compared to 0.05 for the PFA.

Table 3 Analyte Recoveries from Transfer Tube.

\begin{tabular}{|c|c|c|c|c|c|c|}
\hline \multirow[t]{2}{*}{ Sample ID } & \multirow[t]{2}{*}{ Tubing } & \multirow[t]{2}{*}{ Environment } & \multicolumn{4}{|c|}{$\%$ Recovery } \\
\hline & & & TCE & Toluene & $P C E$ & m-Xylene \\
\hline Initial Conc. & $\mathrm{N} / \mathrm{A}$ & Ambient & $99 \%$ & $110 \%$ & $99 \%$ & $101 \%$ \\
\hline Initial Conc. & $\mathrm{N} / \mathrm{A}$ & Ambient & $102 \%$ & $106 \%$ & $101 \%$ & $105 \%$ \\
\hline \multirow[t]{2}{*}{ Initial Conc. } & $\mathrm{N} / \mathrm{A}$ & Ambient & $98 \%$ & $84 \%$ & $100 \%$ & $94 \%$ \\
\hline & & Averages & $100 \%$ & $100 \%$ & $100 \%$ & $100 \%$ \\
\hline Final \#1 & FEP & Ambient & $89 \%$ & $107 \%$ & $103 \%$ & $115 \%$ \\
\hline Final \#2 & FEP & Ambient & $89 \%$ & $85 \%$ & $96 \%$ & $107 \%$ \\
\hline \multirow[t]{2}{*}{ Final \#3 } & FEP & Ambient & $92 \%$ & $88 \%$ & $100 \%$ & $111 \%$ \\
\hline & & Averages & $90 \%$ & $93 \%$ & $100 \%$ & $111 \%$ \\
\hline Final \#1 & FEP & Elevated & $92 \%$ & $88 \%$ & $101 \%$ & $107 \%$ \\
\hline Final \#2 & FEP & Elevated & $92 \%$ & $91 \%$ & $99 \%$ & $115 \%$ \\
\hline \multirow[t]{2}{*}{ Final \#3 } & FEP & Elevated & & & & \\
\hline & & Averages & 92\% & $89 \%$ & $100 \%$ & $111 \%$ \\
\hline
\end{tabular}

\begin{tabular}{l|l|l|r|r|r|r|}
\hline Final \#1 & PFA & Ambient & $89 \%$ & $88 \%$ & $91 \%$ & $103 \%$ \\
\hline Final \#2 & PFA & Ambient & $94 \%$ & $94 \%$ & $100 \%$ & $111 \%$ \\
\hline Final \#3 & PFA & Ambient & $94 \%$ & $88 \%$ & $100 \%$ & $115 \%$ \\
\hline
\end{tabular}

\begin{tabular}{|c|c|c|c|c|c|c|}
\hline Final \#1 & PFA & Elevated & $79 \%$ & $82 \%$ & $89 \%$ & $99 \%$ \\
\hline Final \#2 & PFA & Elevated & $109 \%$ & $123 \%$ & $109 \%$ & $122 \%$ \\
\hline Final \#3 & PFA & Elevated & $112 \%$ & $129 \%$ & $125 \%$ & $141 \%$ \\
\hline & & Averages & $100 \%$ & $111 \%$ & $108 \%$ & $121 \%$ \\
\hline
\end{tabular}


A more complete analysis of the results from the laboratory study was conducted using the hypothesis that the mean sample concentration for each tubing, either heated or unheated, was compared to the mean of the initial concentration of contaminant in the vapor sample bag. The statistics were calculated using the above equations to determine the Student $t$ value for each tubing and each contaminant. Table 4 presents a summary of the calculated Student $t$ values. Assuming a 90\% confidence level, the null hypothesis is rejected for Student $\mathrm{t}$ values greater than 2.13. Analysis of Table 4 indicates that five of the sixteen tests returned statistics that indicate that we should reject the hypothesis that no contamination was adsorbed in the transfer line. Of the five rejections, four were for the FEP tubing, and only one was for the PFA tubing. For the FEP tubing, both heated and unheated caused adsorption of the TCE and $\mathrm{m}$-Xylene contaminants. The only case that caused a rejection for the PFA tubing was the unheated case for TCE. Based upon these strong results, the PFA tubing was selected as the tubing of choice. This testing also supports the need for heated transfer lines as opposed to using standard unheated tubing.

Table 4 Student t-Statistics Calculated from a Comparison of Source Concentration to That Measured After Passing Through the Teflon ${ }^{\circledR}$ Tubing.

\begin{tabular}{|l|l|r|r|r|r|}
\hline \multirow{2}{*}{ Tubing } & \multirow{2}{*}{ Environment } & \multicolumn{4}{|c|}{ t-Statistic } \\
\cline { 3 - 6 } & & \multicolumn{1}{|c|}{ TCE } & Toluene & \multicolumn{1}{c|}{ PCE } & m-Xylene \\
\hline FEP & Ambient & 7.18 & 0.64 & 0.19 & 2.87 \\
\hline FEP & Elevated & 5.40 & 1.03 & 0.16 & 2.15 \\
\hline PFA & Ambient & 3.72 & 1.21 & 0.86 & 2.11 \\
\hline PFA & Elevated & 0.01 & 0.67 & 0.76 & 1.69 \\
\hline
\end{tabular}

Note: $t$-Statistic at $90 \%$ confidence with 4-degrees of freedom $=\mathbf{2 . 1 3}$. Reject $\mathrm{H}_{0}$ if value is greater than 2.13 (e.g., there is a difference in the concentration measured at the source compared to the concentration measured after drawing the gas mixture through the tubings).

\subsection{DTD Probe}

DTD probe testing occurred at two scales; bench testing and field testing. The bench scale test was conducted to determine the heating efficiency of the Dynamic Thermal Desorption (DTP) probe. The field test was conducted to evaluate performance of the DTD integrated with the heated transfer line and up-hole SAW/GC analyzer. 


\subsubsection{Bench Testing}

Bench testing was performed to evaluate the capacity of the DTD probe to transfer heat to the soil with which it comes in contact. The goal of these tests was to use the knowledge gained to optimize volatilization of the target compounds through refinement of the sampling methodology. Volatilization is a process of liquid or solid phase evaporation that occurs when NAPLs or dissolved phase contaminants contact a gas phase. The process itself is controlled by the vapor pressure of the organic solute or solvent. The vapor pressure of a liquid is the pressure of the gas-phase in equilibrium with respect to the liquid-phase at a given temperature. As the temperature increases, so does the respective vapor pressure. Table 5 lists the vapor pressure and boiling point of the target analytes.

Table 5. Volatility Parameters of Target Analytes.

\begin{tabular}{|l|l|l|}
\hline \multicolumn{1}{|c|}{ Target Analyte } & \multicolumn{1}{c|}{$\begin{array}{c}\text { Vapor Pressure } \\
\left(\mathrm{mmHg} @ 68^{\circ} \mathrm{F}\right)\end{array}$} & $\begin{array}{c}\text { Boiling Point } \\
\left({ }^{\circ} \mathrm{C}\right)\end{array}$ \\
\hline Benzene & 75 & 80 \\
\hline Toluene & 20 & 111 \\
\hline Ethylbenzene & 7.08 & 136 \\
\hline o-Xylene & 7 & 144 \\
\hline cis 1,2-DCE & 180 & 48 \\
\hline $1,1,1-\mathrm{TCA}$ & 100.0 & 74.1 \\
\hline TCE & 58 & 87 \\
\hline PCE & 14 & 121 \\
\hline
\end{tabular}

The bench-scale test consisted of embedding the DTD probe in damp soil then energizing the probe, elevating the temperature of both the probe and the surrounding soil. The temperature of the soil adjacent to the probe was monitored with thermocouples at two radial distances from the outer surface of the probe; one at $1 \mathrm{~cm}$ and the other at $2 \mathrm{~cm}$. The results were plotted as a function of time and are shown below in Figure 10. Based on the results of this test, we decided to modify our sampling procedure to maximize desorption of the target analytes. Instead of continually advancing the probe as was done previously, we sampled at discrete intervals, allowing the DTD probe to heat the soil sufficiently to desorb the target analytes with higher boiling points. 
The results from the heating test indicate that it takes approximately 10 to 20 minutes for the soil surrounding the probe to reach an equilibrium temperature. Based upon this information, the sampling approach for the DTD probe has been changed from one of continuously sampling during the penetration process, to sampling at discrete intervals. This allows the probe sufficient time to heat the surrounding soils to a temperature that is sufficient to volatize the chlorinated and halogenated compounds.

\section{Dynamic Thermal Desorption Probe Temperature Profiles \\ 455-Watts}

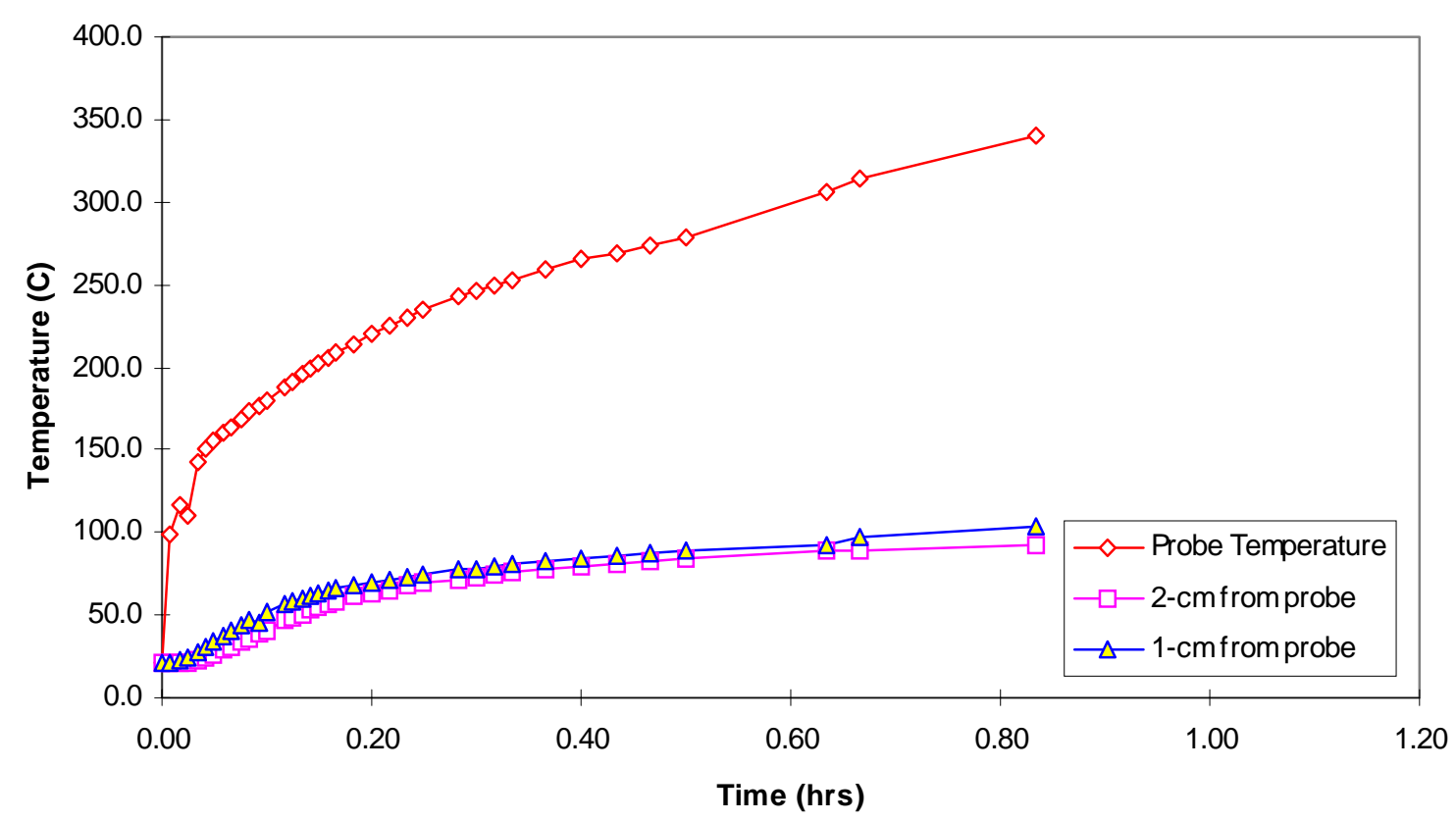

Figure 10. Temperature Profiles from the DTD Probe Measured at the Probe and at Two Radial Distances from the Probe.

\subsubsection{Field Evaluation}

\subsubsection{Soil Sampling}

Although the soil sampling occurred at the end of the field testing effort, we will discuss these results first as they will be a basis of reference throughout the remainder of the Results section. Prior, independent characterization of the demonstration site occurred in June of 1997 when soil cores were collected following a bioventing study conducted within the confines of the test cell. The cores were divided into 4-inch sections, subsampled, and then 
analyzed for total petroleum hydrocarbons, aromatic components of fuel, and chlorinated solvents. The results of these analyses, obtained from Vogel et al, ${ }^{2}$ are included as Appendix A. A review of these data shows the strongest contamination for all species to occur in the interval between six and nine feet below ground surface. JP-4 and BTEX components predominate in this interval, although there are also significant concentrations of PCE, TCE and chlorobenzene. BTEX and TCE are also present in the interval from 14 to 15 feet bgs.

In support of the current effort, three soil samples were collected and analyzed for the volatile organic target compounds in accordance with EPA standard methods for the examination of solid waste (SW-846, method 8260). These results, tabulated in Table 6, correlate well with the baseline data available for this site. This correlation is shown graphically in section 6.3 DTM, below.

Table 6. Chemical analytical results of the soil analyses.

\begin{tabular}{|l|r|r|r|}
\hline \multirow{2}{*}{ Target Analyte } & \multicolumn{3}{|c|}{ Concentrations in Soil (mg/kg) } \\
\cline { 2 - 4 } & \multicolumn{3}{|c|}{ Depth Below Ground Surface, $\mathrm{ft}$} \\
& $6.5-8.5$ & $8.5-10.5$ & $11.0-11.5$ \\
\hline cis 1,2-DCE & $<2$ & $<2$ & $<2$ \\
\hline $1,1,1-\mathrm{TCA}$ & $<2$ & $<2$ & $<2$ \\
\hline TCE & $<2$ & $<2$ & $<2$ \\
\hline PCE & 1.6 & 5.1 & 3 \\
\hline Benzene & $<2$ & $<2$ & $<2$ \\
\hline Toluene & $<2$ & 4.6 & 2.4 \\
\hline Ethylbenzene & 4.4 & 23 & 10 \\
\hline m\&p Xylene & 22 & 105 & 41 \\
\hline o-Xylene & 13 & 49 & 22 \\
\hline Total Fuels & 39 & 182 & 75 \\
\hline Total Solvents & 1.6 & 5.1 & 3 \\
\hline
\end{tabular}

The last two rows of Table 6 highlight that trend with depth, showing the concentrations reach a maximum at approximately 9.5-feet below ground surface (bgs). Ethylbenzene, m-, p-, and o-xylene represent the primary constituents. The only chlorinated constituent detected in the samples was PCE, and it exhibits the same trend with depth.

\footnotetext{
${ }^{2}$ Vogel et al, 1997. Final Report
} 


\subsubsection{SAW/GC Calibration}

Using 10-ppm calibration standards of the target volatile organic analytes, we calibrated the SAW/GC instrument prior to conducting the soundings. The instrument achieves very rapid analysis by greatly abbreviating retention times. This attribute resulted in an inability to discriminate some target analytes from others due to co-elution of their peaks. Additionally, instability in retention times further complicated identification of the individual peaks. Specifically, interferences in retention time occurred between benzene and 1,1,1-TCA; toluene from PCE; and ethylbenzene and $\mathrm{m}$ - and p-xylene. Table 7 lists the compounds and their respective retention times noted during initial calibration.

Table 7. Retention times for the target analytes specific to this study. Note that several peaks co-elute.

\begin{tabular}{|l|c|}
\hline Target Analyte & $\begin{array}{c}\text { Retention Time } \\
\text { (seconds) }\end{array}$ \\
\hline cis 1,2-DCE & 4.78 \\
\hline $1,1,1-$ TCA \&/or Benzene & 5.16 \\
\hline TCE & 5.68 \\
\hline Toluene \&/or PCE & 6.48 \\
\hline Ethylbenzene \&/or m\&p Xylene & 8.06 \\
\hline o-Xylene & 8.52 \\
\hline
\end{tabular}

\subsubsection{SAW/GC Performance}

During the course of field testing the probes, quality control analyses indicated the SAW/GC was performing inconsistently and deficiently. Following the field evaluation of the CPT tools using the SAW/GC, we discovered the instrument had been received with several defects, which contributed to this impaired performance. Upon return, the manufacturer determined the instrument had a loose and improperly functioning flow regulator and a worn sampling valve rotor. These factors resulted in inconsistent carrier gas flow and partial obstruction of the sample and carrier flow path by shredded Teflon ${ }^{\circledR}$ and other possible physical impurities from the broken valve. Although eventually corrected by the manufacturer, these problems were likely present throughout the duration of the field testing effort and impacted the quality of the analytical results. However, results were obtained which, subject to 
some qualitative adjustments in interpreting the output of the SAW/GC instrument, are of value in assessing the performance of the DTD and heated transfer line.

\subsubsection{Discussion}

A total of 20 discrete samples were collected from separate elevations at 0.5 -foot intervals beginning at 2.0 feet and continuing to 11.5 feet bgs.

Table 8 lists the sounding details for all of the testing that occurred during the course of this study.

Table 8. Sampling details for all the GC analyses conducted during the field testing program.

\begin{tabular}{|c|c|c|c|c|}
\hline File ID & $\begin{array}{c}\text { Sample Port Depth } \\
\text { (ft) }\end{array}$ & $\begin{array}{c}\text { Transfer Temp } \\
\left({ }^{\circ} \mathbf{C}\right)\end{array}$ & $\begin{array}{c}\text { DTD Temp } \\
\left({ }^{\circ} \mathbf{C}\right)\end{array}$ & $\begin{array}{c}\text { Flow } \\
\text { Scale Units }\end{array}$ \\
\hline 98061109.533 & 1.9 & 91.3 & 27.5 & 45 \\
\hline 98061109.583 & 2.5 & 98.4 & 37.1 & 45 \\
\hline 98061110.034 & 3.0 & 101.8 & 40.0 & 45 \\
\hline 98061110.084 & 3.5 & 102.0 & 43.0 & 45 \\
\hline 98061110.180 & 4.0 & 106.5 & 56.0 & 45 \\
\hline 98061110.545 & 4.5 & 112.5 & 61.5 & 42 \\
\hline 98061111.093 & 5.0 & 113.4 & 84.2 & 42 \\
\hline 98061113.142 & 5.5 & 101.9 & 43.7 & 42 \\
\hline 98061113.375 & 6.0 & 108.0 & 88.6 & 45 \\
\hline 98061113.482 & 6.5 & 110.9 & 95.7 & 40 \\
\hline 98061114.093 & 7.6 & 113.8 & 55.8 & 43 \\
\hline 98061115.052 & 8.6 & 116.7 & 63.7 & 43 \\
\hline 98061115.310 & 9.0 & 117.5 & 85.7 & 45 \\
\hline 98061116.144 & 9.5 & 118.0 & 79.0 & 46 \\
\hline 98061116.421 & 10.0 & 118.7 & 87.3 & 47 \\
\hline 98061116.570 & 10.5 & 119.2 & 88.0 & 45 \\
\hline 98061117.165 & 11.0 & 119.5 & 75.6 & 48 \\
\hline 98061117.395 & 11.5 & 119.7 & 73.0 & 57 \\
\hline 98061118.514 & 11.5 & 118.0 & 76.5 & 18 \\
\hline 98061119.192 & 7.0 & 118.0 & 78.5 & 40 \\
\hline 98061119.361 & 3.0 & 117.0 & 105.0 & 22 \\
\hline
\end{tabular}

Figure 11 represents a chromatograph of a background sample which will be defined as the concentrations of the target analytes detected in the sample at the two foot depth. Toluene/PCE were the only calibrated peaks found in this sample. This chromatogram will 
serve as a baseline from which to compare chromatograms resulting from deeper samples in the same location.

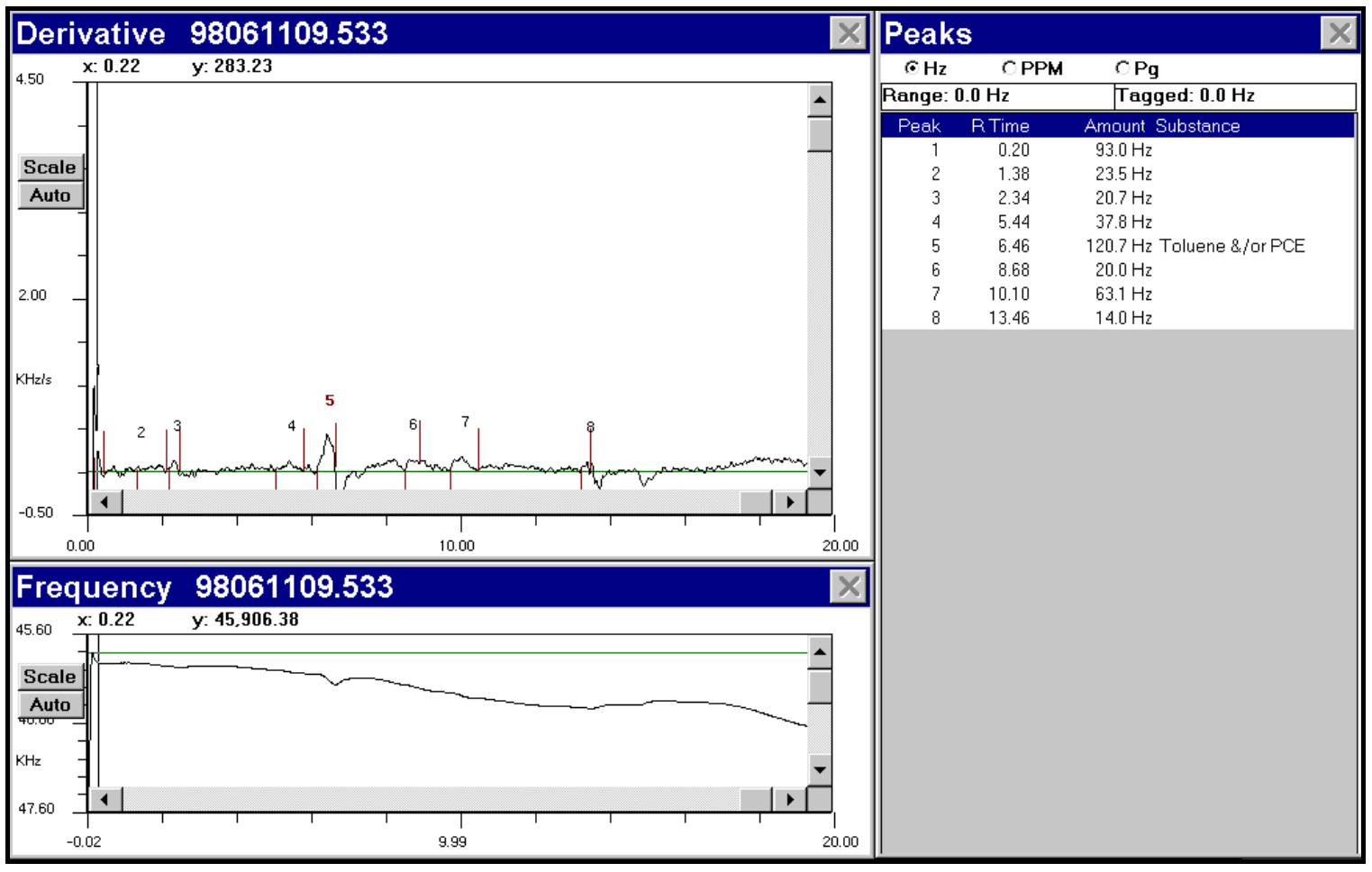

Figure 11. Chromatogram resulting from the soil-gas sample collected at 1.9 feet bgs.

Figure 12 illustrates the chromatogram associated with the soil-gas sample collected at a depth of 4.5 feet bgs. In this chromatogram we start to see some clearly distinguishable peaks with two peaks identified as 1,1,1-TCA/benzene (peak \#5) and ethylbenzene and m- and pxylene(peak \#8), respectively. The overlain chromatogram in Figure 12 (red trace) clearly shows these peaks are above the established baseline chromatogram. 


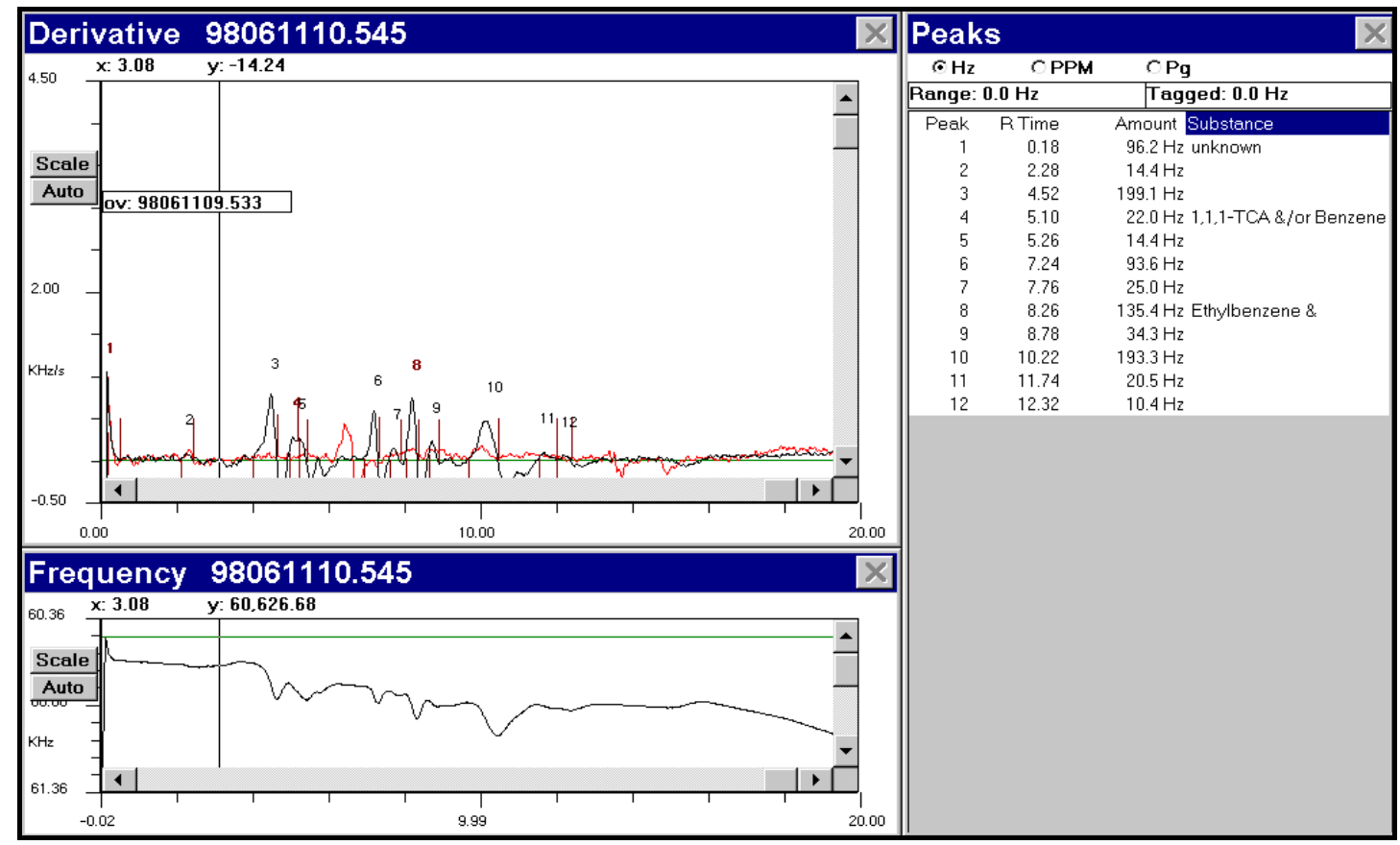

Figure 12. Chromatogram resulting from the soil-gas sample collected at 4.5 feet bgs.

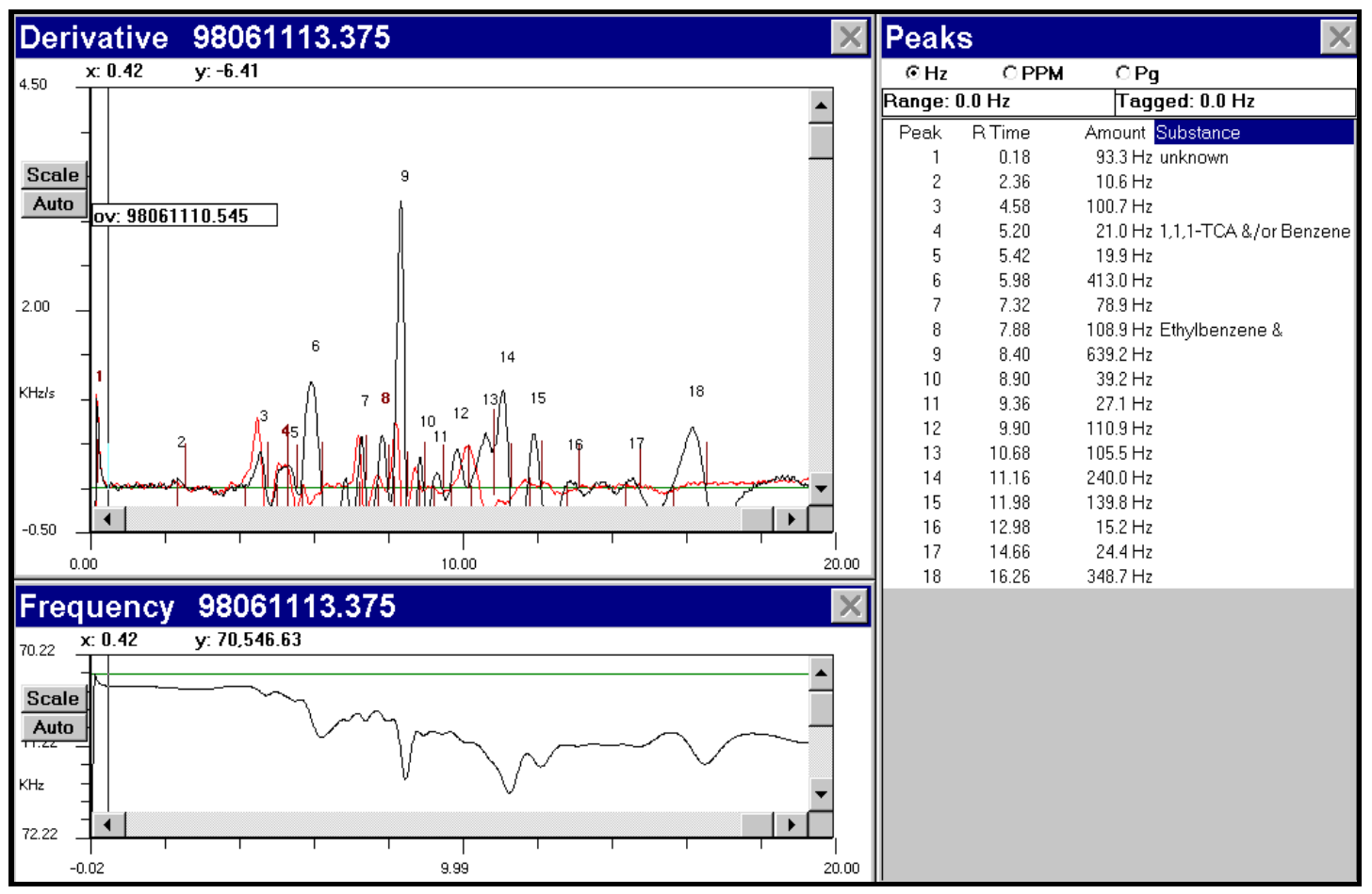

Figure 13. Chromatogram of resulting from soil-gas sample collected at of 6.0 feet bgs (black trace). Note the apparent retention time shift between the 6.0-foot bgs trace and the 4.5-foot bgs trace (red). 
Figure 13 represents the concentration of analytes present in the soil-gas at a depth of 6.0-feet bgs. The chromatogram from the 4.5-foot depth is overlaid (red trace) to show the relative difference in the magnitude of the peaks. Two of the target analytes were detected in this sample; 1,1,1-TCA/benzene (peak \# 4) and ethylbenzene and m- and p-xylene(peak \# 8). The response for the two detected compounds remained about the same. However, the magnitudes of some of the peaks are clearly increasing. The overlay also highlights the instrument problem discussed earlier with regard to temporal variation in retention times. Peak \#9 was not identified as one of the calibrated peaks in the primary chromatogram but, in the overlay, the peak with a similar retention time was identified as Ethylbenzene/m\&p-xylene. Based on the pattern shown by the two traces, we observed that the retention times increased for all of the peaks uniformly. This results in the wrong peak being identified as Ethylbenzene/m\&p-xylene. Based on both the results of the soil sample analyses and the baseline soil data one would expect the ethylbenzene and $\mathrm{m}$ - and $\mathrm{p}$ - xylene to be increasing in this zone, therefore we infer that peak \#9 is in fact ethylbenzene/m\&p-xylene.

The next chromatogram (Figure 14) shows the concentrations of the analytes in the sample collected from a depth of 8.6-feet below ground surface. Three peaks were identified based on calibration table; toluene/PCE (peak \# 6), ethylbenzene and m- and p- xylene (peak \# 9), and o-xylene (peak \# 10). An overlay from the 6-foot depth is shown (red trace) and, once again, indicates that the retention times have shifted (e.g., increased) somewhat. In this chromatogram, a retention time instability causes the ethylbenzene (\# 10, 8.06-second calibration retention time) to be identified by the instrument as o-xylene. 


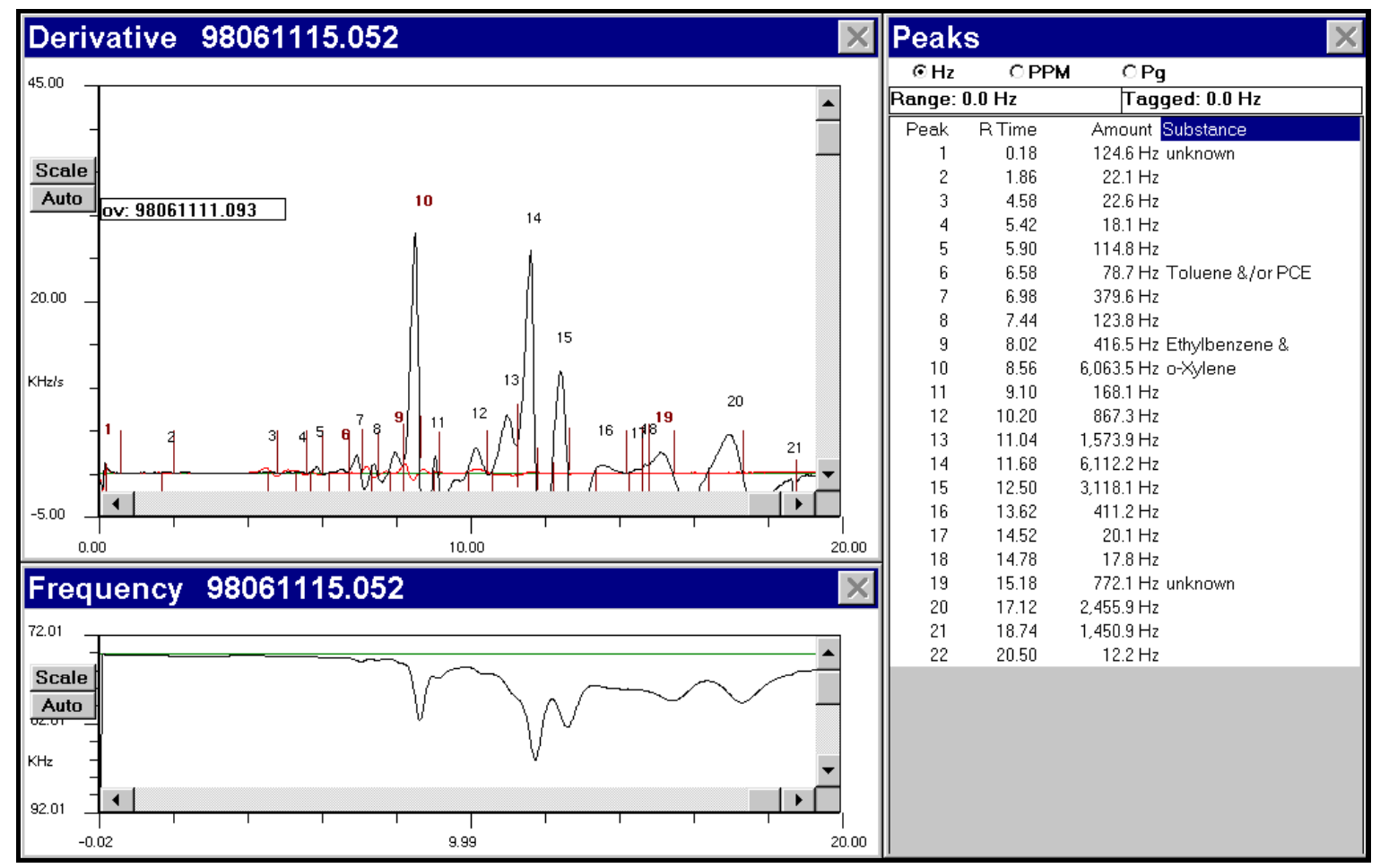

Figure 14. Chromatogram resulting from soil-gas sample collected at 8.6-feet bgs with ethylbenzene and mand p- xylene peak (\#10) incorrectly identified as o-xylene due to retention time instability.

The next few chromatograms show similar patterns but apparently the detector was overloaded by the peak occurring at approximately 8.3 seconds, which corresponds to the retention time of ethylbenzene and $\mathrm{m}$ - and p-xylene. Low concentrations of cis-1,2-DCE and TCE began to appear at 9.5 and 10.0 feet bgs. Figure 15 shows a chromatogram typical of these depths. Concentrations of detected analytes appear to have peaked at a depth of approximately 10.0 to 10.5 feet bgs. 


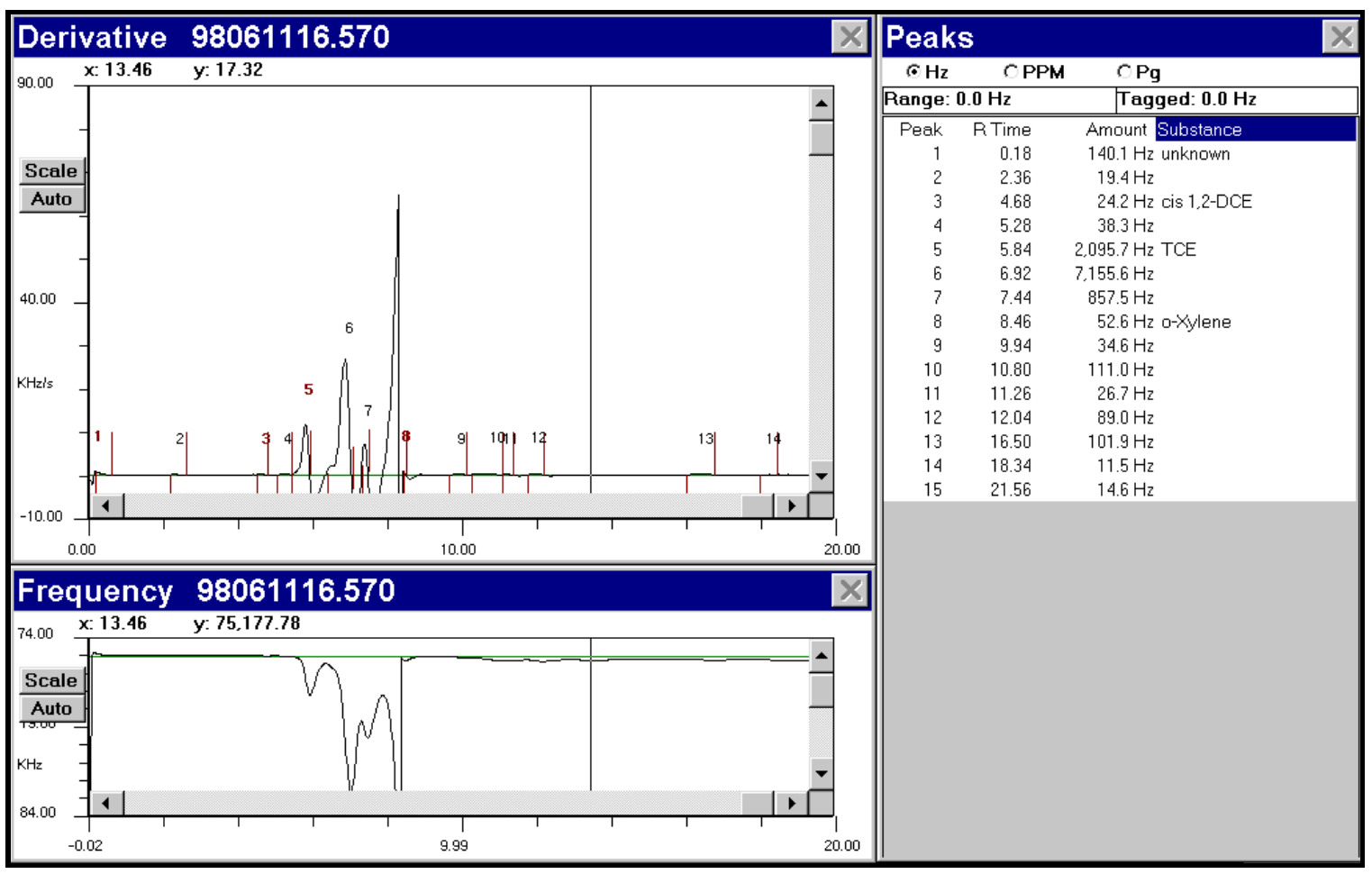

Figure 15. This chromatogram shows the results from a sample collected from a depth of 10.5-feet below grade. Note that the detector overloaded at approximately 8.4-seconds.

Carryover from sample to sample was a problem with the SAW/GC. Below is a chromatogram (Figure 16) of a sample collected at a depth of 8.6 feet bgs (black trace).

Overlain (red trace) is a chromatogram from a nitrogen blank injected directly into the GC (bypassing the entire DTD/Transfer line system). The peak identified as o-xylene showed a response of $6063-\mathrm{Hz}$ in the sample and approximately $300-\mathrm{Hz}$ in the blank. This response to the blank falsely indicates a concentration of approximately $4 \mathrm{ppm}$. To obtain accurate detector response, the instrument carryover necessitated purging the instrument between samples with numerous nitrogen blanks. Because such purging cannot be accomplished during the contiguous sampling integral to screening mode operation, evaluation of the DTD probe in screening mode was not possible. As such, no screening mode testing was performed. It should be noted, however, that this condition was due to a limitation of the faulty up hole SAW/GC instrument, not a limitation of the DTD Probe. 


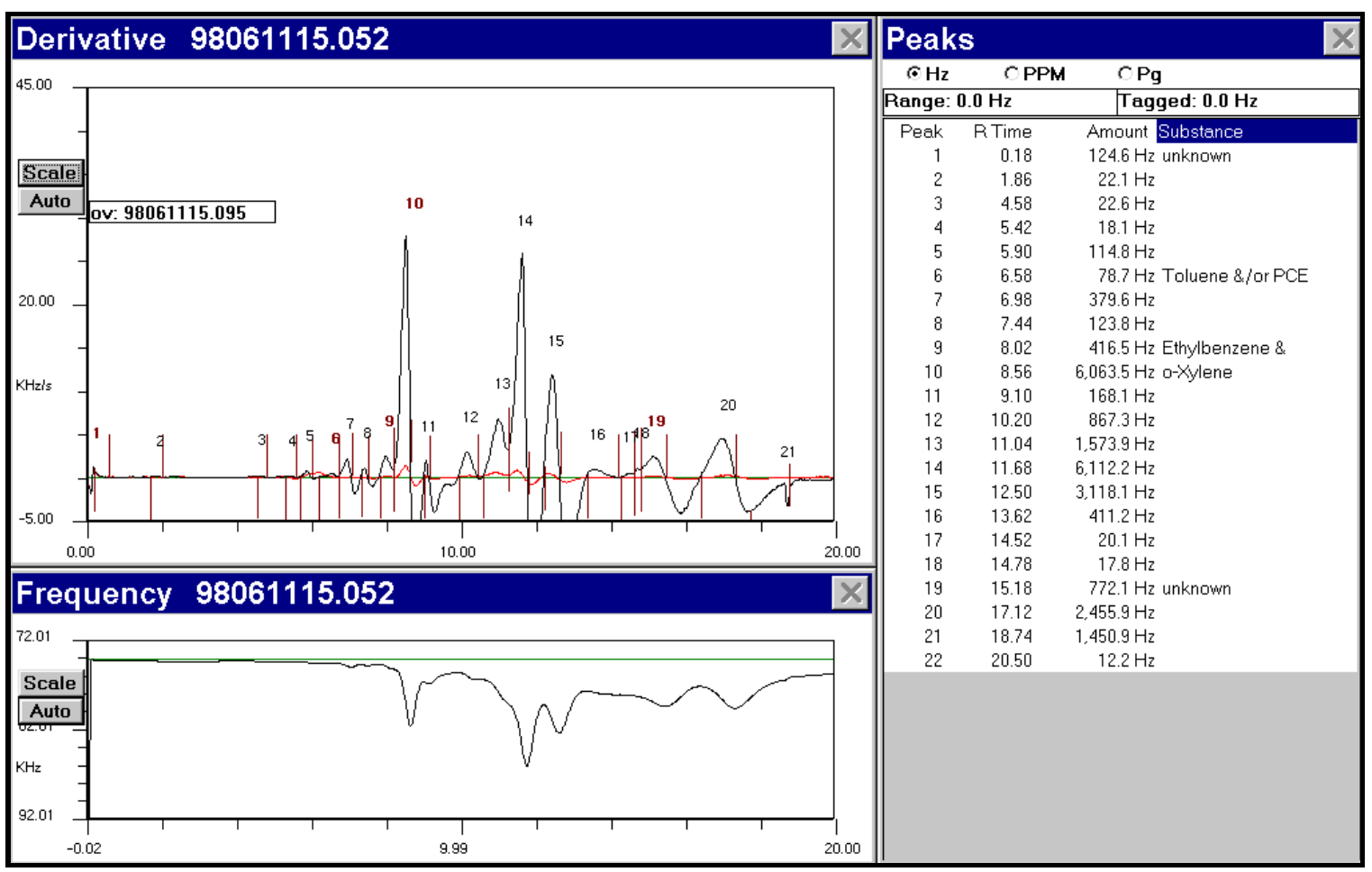

Figure 16. Chromatogram of soil-gas sample from 8.6 feet bgs (black trace), overlain by chromatogram from instrument nitrogen blank (red trace) showing carryover equivalent to $4 \mathrm{ppm}$ xylene.

\subsubsection{Findings}

Impaired functionality of the SAW/GC resulted in unstable retention times and sample carryover which precluded screening mode evaluation of the DTD probe and complicated interpretation of the results obtained from discrete DTD sampling. However, the data collected using the SAW/GC and the DTD reproduced the trends shown in both the soil samples collected during this study and in the baseline soil data previously collected by others. These results indicate the DTD can be successfully applied as a screening tool to detect volatile organic contamination in the unsaturated zone and to analyze trends in concentration with depth. However, first the SAW/GC instrument carryover problem must be eliminated or the SAW/GC must be replaced with an instrument that performs as rapid an analysis. Optoacoustic based instruments now exist which can fulfill this role.

Due to variable soil gas pressure, soil moisture content and other soil characteristics with depth, soil-gas concentrations do not directly indicate the concentration of contaminants in the bulk soil matrix. However, these parameters can be measured using other CPT tools (Soil Moisture Sensor, resistivity sensor, piezocone soil classification). The purpose of heating with 
the DTD Probe is to increase the soil gas concentration of VOCs above the ambient equilibrium condition in order to screen more sensitively for contamination in the bulk matrix. Further development of the DTD probe should be undertaken to estimate bulk soil contaminant concentrations from a combination of the DTD soil-gas results, temperature data, and other measurable soil and moisture parameters.

Additional DTD Probe results are discussed below in relation to Down-hole Trap Module (DTM) results.

\subsection{DTM}

The Down-hole Trap Module (DTM) was field evaluated during the same effort and under the same conditions as the DTD probe. Three adsorbent trap samples were collected using the DTM, each from a different depth in the test cell. Samples were obtained by activating the appropriate solenoid valve pairs to divert sample flow through the selected trap using the three-position selector switch on the sampling control panel. The appropriate volume of soil-gas to sample was estimated based on the results of the DTD testing to insure that the traps were not overloaded. The sample gas flow rate was adjusted to 20 milliliters per minute $(\mathrm{ml} / \mathrm{min})$ using the flow regulator on the control panel and monitored with a rotometer. The flow was switched on for exactly one minute resulting in a volume of $20 \mathrm{ml}$ being drawn through each trap. Table 9 lists the concentrations of the target analytes found at the respective depths. 
Table 9. Concentration of Soil-Gas samples collected down-hole on adsorbent traps using the DTM and analyzed by Modified EPA Method TO-1.

\begin{tabular}{|l|r|r|r|}
\hline & \multicolumn{3}{|c|}{ Concentrations in Soil-Gas $(\mu \mathrm{g} / \mathrm{L})$} \\
\hline \multirow{2}{*}{ Target Analyte } & \multicolumn{3}{|c|}{ Depth Below Ground Surface } \\
\hline cis 1,2-DCE & 3.0 & 7.0 & 11.5 \\
\hline $1,1,1-$ TCA & $<2.0$ & $<2.0$ & $<2.0$ \\
\hline TCE & $<2.0$ & $<2.0$ & $<2.0$ \\
\hline PCE & 17.00 & 13.50 & 26.50 \\
\hline Benzene & 25.5 & 12.50 & 18.00 \\
\hline Toluene & $<2.0$ & $<2.0$ & $<2.0$ \\
\hline Ethylbenzene & 33.00 & 22.00 & 22.50 \\
\hline m\&p Xylene & 44.50 & 21.50 & 40.00 \\
\hline o-Xylene & 145.00 & 75.00 & 145.00 \\
\hline
\end{tabular}

Figure 17, Figure 18, and Figure 19 compare the DTM analytical results for BTEX, PCE, and TCE respectively, with the bulk soil analytical results obtained during the present investigation and by Vogel et al during baseline characterization. The baseline data shown represents the average of results from two boreholes flanking that of the present investigation and located approximately equidistant from it. A depth offset of 3.33 feet has been added to the baseline data to make their surface elevation datum coincide with that of the present investigation. The ratio of the DTM scale (right side, $\mu \mathrm{g} / \mathrm{L}$ ) to the soil sample scale (left side, ppm) remains constant at 7.5:1 for all three figures. 


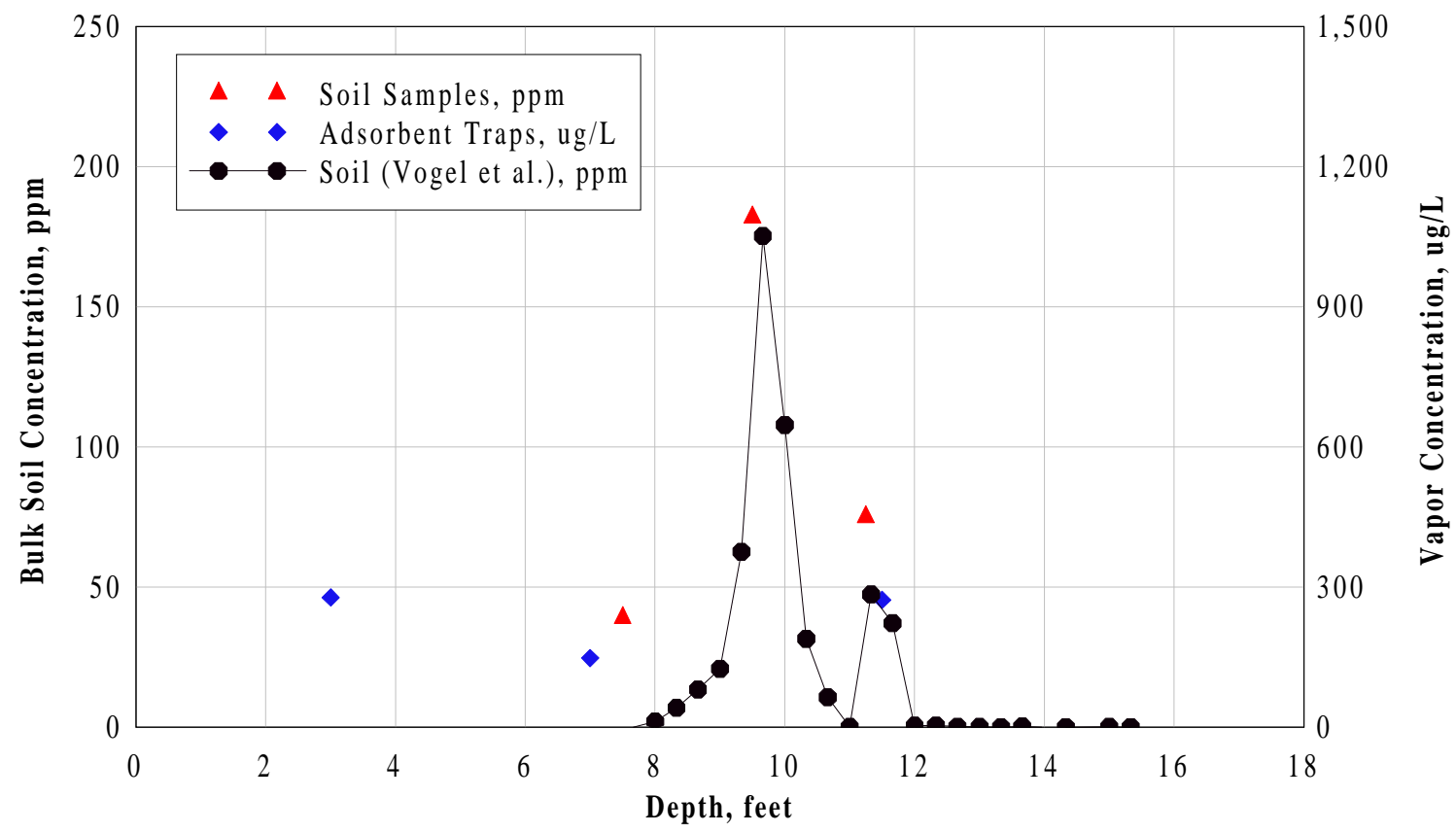

Figure 17 Comparison of DTM analytical results for BTEX (diamonds) with bulk soil analytical results from both the present investigation (triangles) and the baseline characterization (dots).

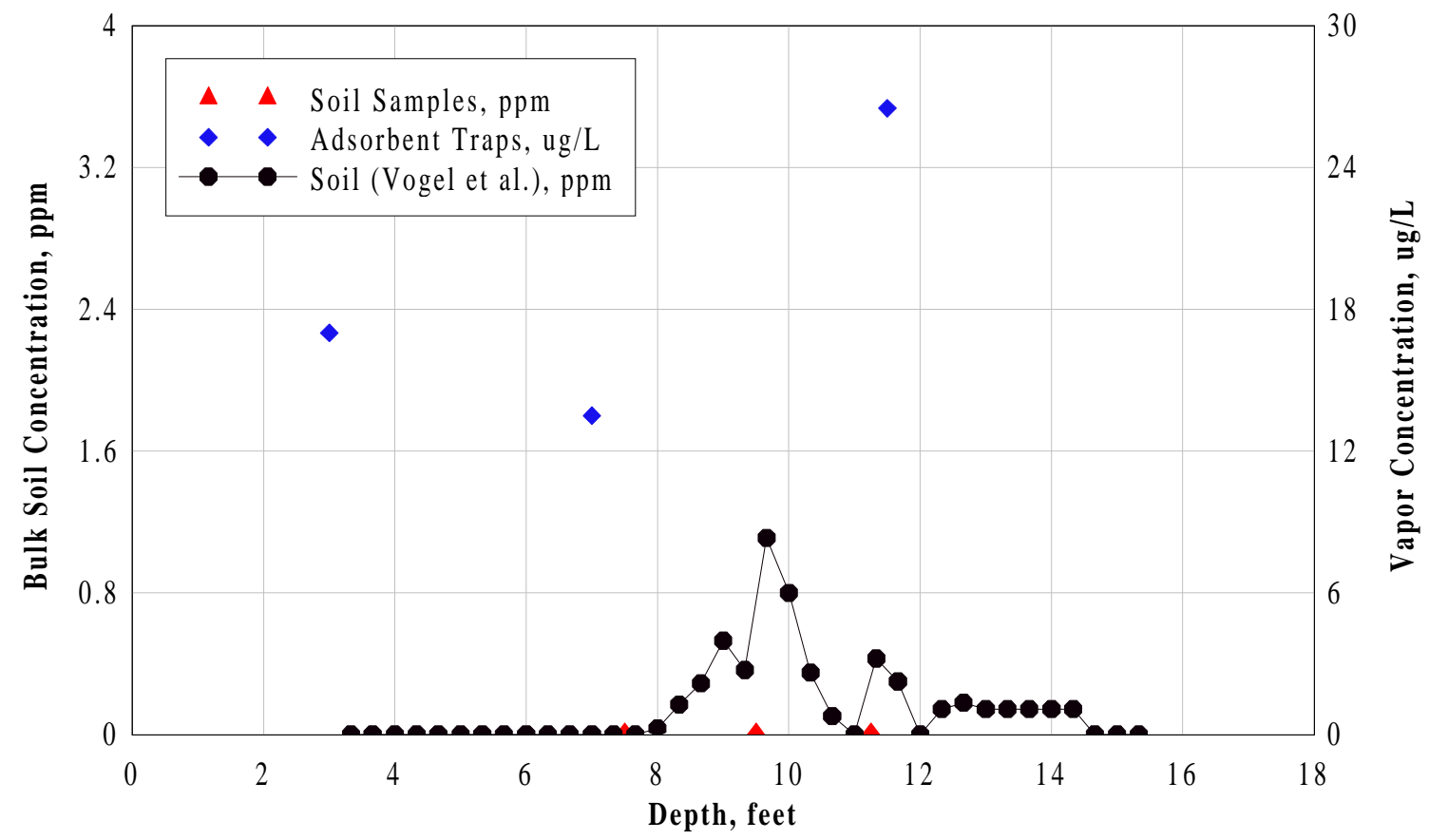

Figure 18 Comparison of DTM analytical results for TCE (diamonds) with bulk soil analytical results from both the present investigation (triangles) and the baseline characterization (dots). 


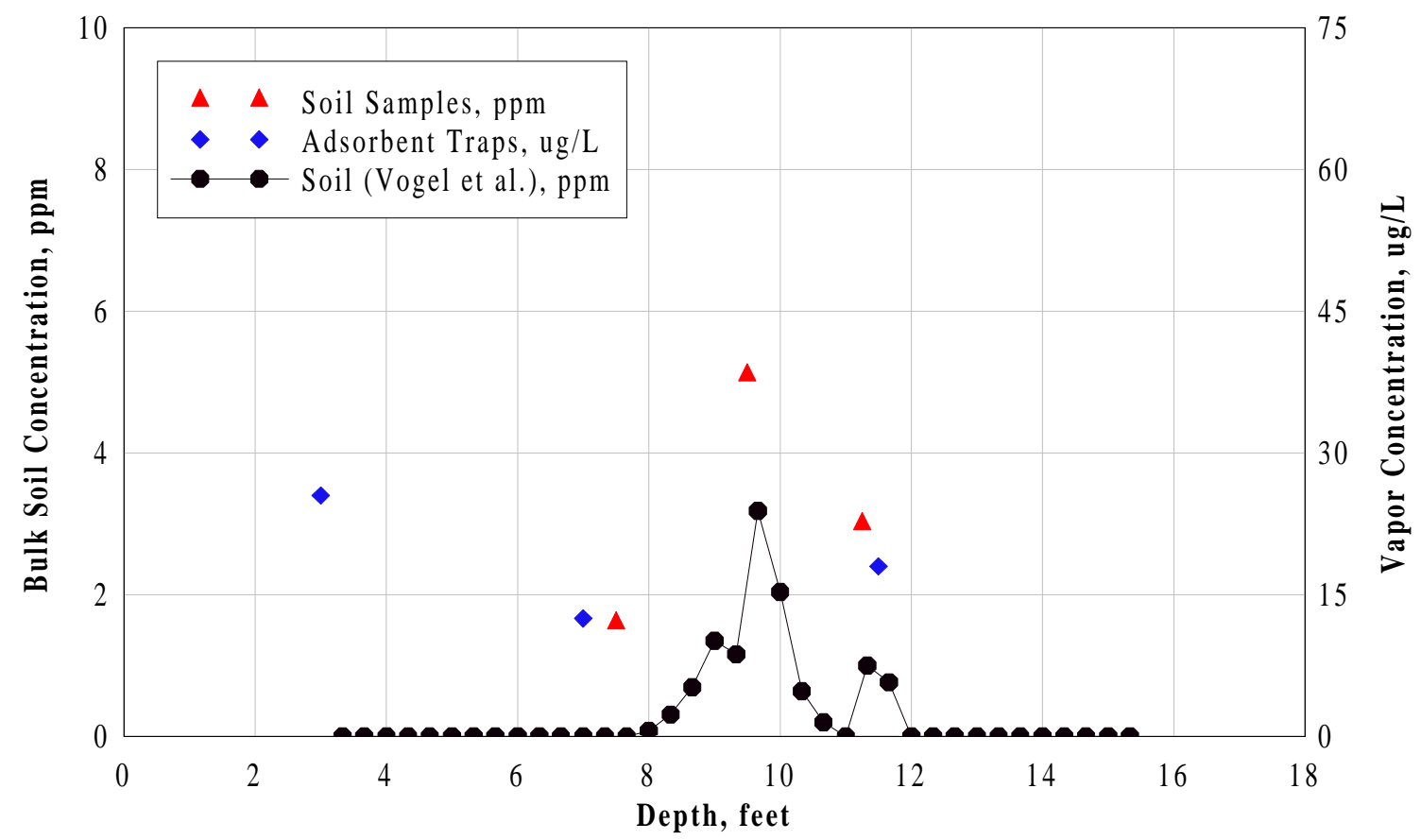

Figure 19 Comparison of DTM analytical results for PCE (diamonds) with bulk soil analytical results from both the present investigation (triangles) and the baseline characterization (dots).

In all three figures, the trend of concentration versus depth observed in the current investigation is consistent with that of the baseline data for both the soil samples and the DTM. Additionally, the ratio of DTM results to bulk soil concentration is relatively constant for both BTEX compounds and PCE, as shown in Figure 17 and Figure 19. However, for TCE (Figure 18) the ratio of DTM-derived concentrations to bulk soil analyses is much greater than for the other constituents. This is an indication that the heating of the soil by the DTD Probe has a varying, compound dependent effect on enhancement of vapor phase concentrations.

Additionally, the bulk soil samples, recovered subsequent to the DTM test, indicate lower TCE concentrations than do the baseline data. This finding further supports the conclusion that the DTD Probe caused a change in the partitioning relation of the TCE in vapor phase relative to the adsorbed and dissolved (likely -- in soil moisture) phases; or in other words, desorption was successfully effected. This result demostrates the utility of the DTD Probe for enhancing screening mode detection limits relative to bulk soil concentration.

\subsection{CISP}

We were unable to collect a measurable amount of groundwater using the CPT In Situ Purge Probe (CISP) during the field testing. Based on: (1) our knowledge of the soils at the 
field evaluation site, (2) the design criteria that went into filter material selection, and (3) the fact that we were able to collect groundwater samples using the standard sampler, we are certain that the problem resulted from the filter's susceptibility to clogging in the soil type in which it was tested.

\subsubsection{Analysis}

During the re-design phase of the CISP filter, the relationship of sample port out diameter to that of the CISP body was constrained by the range of available sizes of perforated tubing used for the sampling filter. Given the choice between a filter diameter slightly smaller than the body diameter and one slightly larger, the latter was selected on the basis that it would provide better hydraulic contact with the formation. This reduces the potential for the probe to carry contaminated water down with it in the dead space between the formation and the filter. However, because the outside diameter of the screen is larger than bodies of the CISP, the soils tend to be further compressed, resulting in a higher stress against the filter material and an increased tendency to clog. The soil within the test cell at the field evaluation site consists of poorly-graded fine to medium angular sands which, when compressed, can reduce the mobile pore space of the soil, resulting in reduced permeability.

\subsubsection{Findings}

The clogging of the CISP sample filter provided a valuable information to guide the design of future filter modifications. A more appropriate design might have a screened section approximately $1 / 4$-inch smaller in OD than the rods cone to allow the formation to expand somewhat, hence allowing groundwater to flow into the sampling port. Downward carryover of sample water could be averted by designing an increase in the diameter of the CISP body just above the top end of the sampling port. Figure 20 illustrates this concept. 


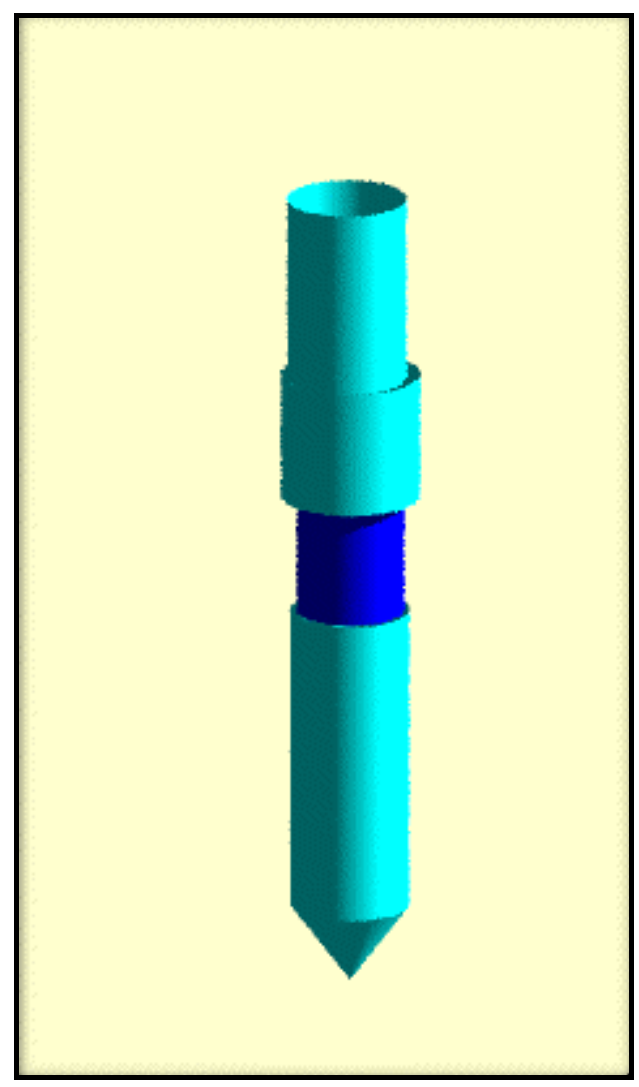

Figure 20. Suggested solution to the filter-clogging phenomenon, while still ensuring against cross- sample carryover. The dark blue section represents the screened portion of the module. 


\section{CONCLUSIONS}

Based upon the development and testing conducted as part of this project, several conclusions can be drawn. These conclusions stem mostly from the field testing but also from the tool development phases of the project. The primary goal of the project was to incorporate into the High Speed GC/CPT system the ability to simultaneously analyze for both chlorinated solvents and aromatic hydrocarbons (BTEX). In addition, general tool improvements were to be made, including the integration of a commercial field GC type unit (the Electronic Sensors Technology, Inc. SAW/GC) into the system. The choice of this analyzer was intended to increase the facility of using the system.

The primary objective was achieved. A new transfer tube material was selected that exhibits no significant retention or degradation of either the chlorinated or the aromatic compounds tested in the detailed laboratory study. Additionally, the field testing of the DTD probe, DTM, and heated transfer line with the SAW/GC provided quantitative and qualitative verification of the contaminant distribution previously established at the test site. This included the detection and quantification of BTEX compounds, TCE, and PCE at depths of 0 to 11 feet below grade at the site.

Additionally, it was demonstrated in relation to TCE that the DTD Probe achieves the desired result of driving bulk soil matrix contamination preferentially into the vapor phase via heating. This action lowers the bulk concentration detection threshold and increases signal to noise ratio -- both valuable effects for enabling rapid screening with High Speed GC/CPT.

Difficulties with the ability to consistently collect sample water into the CPT In Situ Purge Probe (CISP) were not remedied during this effort. The CISP is still hampered by a filter design that becomes clogged in fine-grained soils. Despite a significant modification of the sample inlet port filter design, the CISP was unable to extract an analyzable volume of groundwater from the geology present at the test site. In the next section, we have included a specific recommendation for overcoming this sensitivity to geologic conditions in the CISP sample inlet design. 
In summary, the major objective of incorporating the capability of detecting both BTEX and chlorinated compounds in a single test system has been achieved. The transfer line has been improved and the DTD sampler worked well in the field study. Below, we present recommendations for further improvement and enhancement of the system both in reliability and utility. 


\section{RECOMMENDATIONS}

Based upon the research conducted under this project, we advance three specific recommendations for improvement.

First, we recommend a dramatic re-configuration of the sample inlet port on the CISP. As it is apparent that several filter materials can become clogged as the probe is advanced through fine-grained material, the approach we recommend for future development is to shield the filter from direct contact with the soil until the operator desires to collect and analyze a groundwater sample. This can be accomplished by a sliding shield, which exposes the sample inlet port upon a slight retraction of the CPT rod string. The port would be re-shielded when penetration is resumed. Additionally, a greater volume of groundwater than required could be sampled to flush the inlet path, reducing the potential for carryover of contamination between samples.

Another possible approach is to provide continual out-flow of inert gas or water through the sample filter while penetrating in order to prevent filter-clogging material from entering the filter pore space. Success has recently been demonstrated at SRS using this approach with ARA's ConeSipper®.

Second, we recommend a more efficient heating design for the DTD probe. Recent advances in ohmic (or resistive) heating of soil for remediation applications have provided a solid body of experimental data and modeling techniques that readily facilitate conversion of the probe from a conduction heating device to a direct heating device. This conversion would allow not only direct measurement of the power dissipated in the soil, but accurate modeling of the soil temperature enabled by estimates of thermal conductivity and resistivity. The estimates of thermal conductivity and resistivity could be derived from measured soil moisture content. This measurement would be obtained by adding ARA's capacitance-based Soil Moisture Sensor (Shinn, Timian, Morey, 1997) the space reclaimed by elimination of the internal heating element. Soil resistivity may also be measured directly. Design changes would provide a basis for quantitative assessment of the concentration of contaminants in the bulk soil matrix. This 
approach would represent a quantum improvement over the DTD probe's current capability only to detect contamination and provide assessment of its relative strength.

Finally, we recommend that additional field studies be conducted, including a comparison of additional portable up-hole analyzers in field use with the CPT tools. The down-hole components of the system are developed to a point that nearly any up-hole gas analyzer can be utilized with the CPT tools. During this project, the EST SAW/GC did not prove to be very effective, however, it is uncertain whether the problems encountered were endemic to the instrument design or whether they were due solely to instrument damage during shipment. Therefore, a comparison of other instrument designs alongside the EST SAW/GC is recommended. To confirm the general conclusions reached in this study, the system should be evaluated in a variety of site conditions, preferably at DoE sites. The new study plan should separate the evaluation of up-hole analyzers from evaluation of the individual CPT tools. By conducting single component evaluations in this manner, the potential for poor performance of a single component will not jeopardize the ability to meaningfully evaluate other components. After individual evaluation of the components, the integrated system should be tested in a variety of site conditions at active DoE sites.

We hold strongly that implementation of the above recommendations will result in a characterization and monitoring tool of demonstrably great utility and imminent commercial applicability to DoE sites. 


\section{REFERENCES}

Kufs, Charles, T., "Statistical Modeling of Hydrogeologic Data - Part I: Regression and ANOVA Models," Groundwater Monitoring Review, Spring, 1992.

Shinn II, James D., PE, David A. Timian, PE, Rexford M. Morey, et. al., "Development of a CPT Deployed Probe for in situ Measurement of Volumetric Soil Moisture Content and Electrical Resistivity," December 31, 1997.

Staples, E.J., G.W. Watson, and W. Horton, "Spectral Density of Frequency Fluctuations in SAW Sensors," 186th Meeting of the ElectroChemical Society, Miami Beach, Florida, October 9$14,1994$.

Staples, E.J. and G.W. Watson, “GC/SAW Non-Intrusive Inspection System,” White House Conference, Office of National Drug Control Policy, New Hampshire, October 1995.

US EPA, "VOA in Ambient Air in Canisters - Method 1(B)," Contract Laboratory Statement of Work, Revision VCAA010.0, 1988.

United States Patent No. 5,289,715, Vapour Detection Apparatus and Method Using an Acoustic Interferometer.

VOA in Ambient Air in Canisters - Method 1(B), Contract Laboratory Statement of Work, Revision VCAA010.0, U.S. EPA. 1988.

Vogel, C.M., B.C. Alleman, J.T. Wilson, D. Kampbell, “In-Situ Co-Oxidation of Chlorinated Solvents During Bioventing of Petroleum Hydrocarbons," Final Technical Report, Air Force Research Laboratory, Airbase and Environmental Division, Tyndall AFB, FL, 1997.

Watson, G.W. and E.J. Staples, "SAW Resonators as Vapour Sensors," Proceedings of the 1990 Ultrasonics Symposium, pp.311-314, 90CH2938-9 